\title{
Emergency Contraceptive Pills: South East Asia Regional Training Manual
}

Sharif M.I. Hossain

Population Council

M.E. Khan

Population Council

Md. Moshiur Rahman

Population Council

Mary Philip Sebastian

Population Council

Follow this and additional works at: https://knowledgecommons.popcouncil.org/departments_sbsr-rh How does access to this work benefit you? Let us know!

\section{Recommended Citation}

Rahman, Md. Moshiur, M.E. Khan, Sharif M.I. Hossain, and Mary Philip Sebastian. 2005. "Emergency Contraceptive Pills: South East Asia Regional Training Manual." New Delhi: Population Council. 


\title{
EMERGENCY CONTRACEPTIVE PILLS
}

South East Asia Regional Training Manual

\section{Contributors}

\author{
Sharif Mohammed Ismail Hossain \\ M. E. Khan \\ Moshiur Rahman \\ Mary Philip Sebastian
}

December 2005

This publication was funded by the U. S. Agency for International Development (USAID) under the terms of cooperative Agreement Number HRN-A-98-00012-00. The opinions expressed herein are those of authors and do not necessarily reflect the views of USAID. 


\section{(P Population Council FRONTIERS}

Frontiers in Reproductive Health Program (FRONTIERS) seeks to improve people's lives by enhancing services in family planning, safe motherhood, and other reproductive health areas.

The Program conducts Operations Research in collaboration with developingcountry organizations to design innovative interventions for improving services. One of the main goals is to communicate these research results so they can be utilized for program and policy development. FRONTIERS Program also works to build the capacity of local organizations to conduct operations research and utilize best practices that emerge from the studies.

FRONTIERS is funded by the U.S. Agency for International Development (USAID) and implemented by the Population Council in partnership with Family Health International.

Frontiers in Reproductive Health Program (FRONTIERS)

53, Lodi Estate

New Delhi- 110003 , India.

Website: http://www.popcouncil.org/frontiers/ 


\section{Contents}

Foreword

Page

Acknowledgments

vii

ix

About the Manual

SESSION 1

Emergency Contraceptive Pills: A Reproductive Health Intervention

Session Objectives and Running the Session

a) Population and fertility in South and South-East Asia 8

b) Contraceptive use 8

c) The extent and causes of maternal mortality 10

d) Menstrual regulation/abortion levels and trends 12

e) How can these unwanted deaths and morbidities be prevented?

f) Role of emergency contraception in reproductive health programs

g) Points to remember about ECP

SESSION 2

Emergency Contraception and Emergency Contraceptive Pills

Session Objectives and Running the Session

a) What is emergency contraception and emergency contraceptive pills?

b) When can emergency contraception be used?

c) What are the methods of emergency contraception?

d) How do emergency contraceptive pills work?

e) What are the indications and contraindications of emergency contraceptive pills?

f) What are the characteristics of emergency contraceptive pills?

g) What is the suggested regimen for emergency contraceptive pills?

h) How should emergency contraceptive pills be taken? 
i) How should the three-day (72 hours) interval be calculated? 26

j) How effective are emergency contraceptive pills? 26

k) Are emergency contraceptive pills effective as regular contraceptive method?

1) Do emergency contraceptive pills have any side effects? 28

m) How can side effects be managed? 28

\section{SESSION 3}

Service Delivery Guidelines for Emergency Contraceptive Pills

Session Objectives and Running the Session

a) Who can provide services for emergency contraceptive pills?

b) To whom should services for emergency contraceptive pills be provided?

c) What services should providers offer?

d) How services should be provided to clients who have requested for emergency contraceptive pills?

e) What should be done in case of regular contraceptive method failure?

f) What should be done if emergency contraceptive pills fail and the client becomes pregnant?

SESSION 4

Counseling on Emergency Contraceptive Pills

Session Objectives and Running the Session

a) Whom to counsel and about what?

b) Frequently asked questions about emergency contraceptive pills

\section{Bibliography}

Appendix

Pre-test questionnaire $\quad 63$

Post-test questionnaire $\quad 65$

Answer key 67

Counseling skills checklist $\quad 68$

Monitoring and supervision checklist 69

Monitoring checklist for training of trainers $\quad 70$ 


\section{List of Tables, Figures and Boxes}

Table 1: Fertility trend in selected countries

Table 2: Prevalence of contraceptive use and unmet need in selected countries

Table 3: Estimates of number of maternal deaths, life time risk and maternal mortality ratio by MDG regions, 2000

Table 4: Global and regional estimates of the number of unsafe abortions and mortality due to unsafe abortion, 2000

Table 5: What is the recommended dose of regular contraceptive pills for use as emergency contraception?

Figure 1: Birth rate around the world 8

Figure 2: Causes of maternal deaths worldwide $\quad 10$

Figure 3: Contraceptive options after emergency contraceptive treatment

Box 1: Abortion and maternal mortality, the global scenario 


\section{Foreword}

Unplanned and unwanted pregnancy is one of the leading causes of maternal mortality and morbidity in South Asia. It is assumed that most women with unwanted/unplanned pregnancies do not continue the pregnancy to the full-term and try to terminate it, often by traditional and harmful methods leading to serious health consequences. Despite the availability of a range of modern and effective contraceptives, unwanted and unplanned pregnancies continue to occur. Proportion of such unwanted pregnancies is subsequently high in South Asian countries. In India, although the Family Welfare Program has made commendable success in helping couples to achieve their desired family size, unplanned pregnancy continues to be a concern. According to the National Family Health Survey carried out in 1998-99, 21 percent pregnancies are unplanned, contributing towards more than 6.5 million induced abortions every year. Many of these unfortunate morbidities could be avoided by the timely use of emergency contraceptive pills. Emergency contraceptive pills could also help in reducing the number of unwanted pregnancies. These are the considerations that have led the Ministry of Health and Family Welfare to approve the introduction of emergency contraceptive pills in the National Family Planning Program.

This training manual on emergency contraceptive pills is an important step in the introduction of the method. It aims to equip trainers with appropriate knowledge and skills on emergency contraceptive pills. Trainers will need one day training to get fully acquainted with emergency contraception method as well as the training materials. After training, trainers will have the knowledge and skills necessary to train service providers and workers on emergency contraceptive pills. Clinicians and program mangers who wish to provide services for emergency contraceptive pills or get acquainted with the method will also benefit from this manual. The manual also provides details about service delivery and counseling guidelines. 
I congratulate the FRONTIERS Program of Population Council and those who have drafted, tested and finalized this manual. I hope this will fulfill the needs of the trainers as well as other professionals to learn about emergency contraception and in explaining about emergency contraceptive pills especially to women who want to use it.

Prasanna Hota, I.A.S.

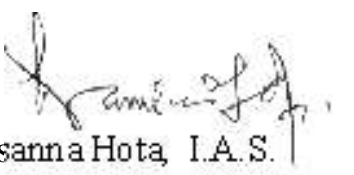

Secretary, Health and Family Welfare

Ministry of Health and Family Welfare

Government of India

December 14, 2005 


\section{Acknowledgments}

The development of the "Emergency Contraceptive Pills: A Training Manual" is an ongoing process of the scaling up activities of Emergency Contraception in the National Family Planning Program of Bangladesh and the result of collaboration between many individuals and organizations including governments.

The Bangladesh Emergency Contraceptive Pills (ECP) training manual was a collaborative effort between Population Council and the Directorate General of Family Planning, Government of Bangladesh as part of the materials to promote emergency contraceptive pills under the National Family Planning Program. The manual was based, to a large extent, on available training modules, handbooks and experiences gained during operations research conducted in Bangladesh by Population Council in collaboration with Directorate General of Family Planning, Pathfinder International and John Snow Inc. This South East Asia regional training manual is largely based on that manual. The authors like to acknowledge Dr. Jahiruddin Ahmed, Dr. Mirza A. H. M. Barek and Dr. Bishnupada Dhar's contributions in developing the Bangladesh ECP manual.

The persons who have contributed significantly during the development of this manual by reviewing and giving constructive comments include Dr. John Townsend, Director, Frontiers in Reproductive Health Program of Population Council, Dr. Emma Ottolenghi, the then Senior Program Associate, Population Council, Dr. Shabnam Shahanaz, Pathfinder International, Dr. Shah Reazul Islam Chowdhury and Dr. S. M. Nizamul Haque of EngenderHealth. We are thankful to all of them. We highly appreciate the secretarial assistance provided by Mr. Tapon Kumar Bose of Population Council.

Finally, we like to thank USAID for the financial support provided to publish the manual. 


\section{About The Manual}

This manual aims to equip Master Trainers with appropriate knowledge on emergency contraceptive pills. Emergency contraception refers to any method of contraception that can be used by a woman to prevent an unwanted pregnancy within three days of unprotected intercourse or a contraceptive accident such as condom leakage. There are two methods of emergency contraception - taking a course of emergency contraceptive pills or using an intra-uterine device (IUD). This manual discusses emergency contraceptive pills and the provision of related services. It does not cover IUDs.

Master Trainers will need a day's training to get acquainted with the training materials. After training, Master Trainers will have the knowledge and skills necessary to train service providers and workers on emergency contraceptive pills. Clinicians and program mangers who would like to provide services or information on emergency contraceptive pills would also benefit from the manual.

The manual is divided into four sessions. The first session provides an overview of the demographic and reproductive health situation in South Asia and briefly discusses the role of emergency contraception as a reproductive health intervention. The second session defines emergency contraception, and discusses details of when and how emergency contraceptive pills should be taken. Service delivery guidelines are covered in the third session, particularly what users should do in case of method failure. The fourth session covers counseling on emergency contraceptive pills and the frequently asked questions on emergency contraception.

Each session has a list of objectives that are detailed at the outset. Master Trainers should aim to achieve these objectives when training service providers and workers. A set of transparencies is provided with the manual to the trainers, which can be used for each session. The information in each session can be presented easily. An overhead projector is needed for the transparencies. An informal questions and answers session should follow each presentation, during which participants can clarify doubts. 
Emergency Contraceptive Pills: A Reproductive Health Intervention 


\section{Session 1}

\section{Emergency Contraceptive Pills: A Reproductive Health Intervention}

\section{Objectives}

By the end of Session 1 participants will know:

- Population and fertility in South and South-East Asia

- Contraceptive use and unmet need in South and South-East Asia

- The levels and causes of maternal mortality world wide

- The extent of menstrual regulations/abortions

- How to reduce the number of unwanted pregnancies, menstrual regulation/abortion and maternal deaths

- Role of emergency contraception in reproductive health programs

\section{Methods/Presenting Session}

The following methods should be used.

a. An overhead projector for the transparencies

b. An informal discussion and question-answer session should follow where participants can clarify their doubts

\section{Time Needed for Session 1}

Presentation: 30 minutes

Discussion and question-answer session: 30 minutes 


\section{Emergency Contraceptive Pills: A Reproductive Health Intervention}

Each year about 210 million women around the world become pregnant (CDC 2004, PRCH and AGI 2003, WHO/SEARO 2001, AGI 1999 and UNFPA 1997). Among them, about 75 million pregnancies (36 percent) are unplanned and/or unintended (WHO/SEARO 2004 and UNFPA 1997). Most of these unplanned/unintended pregnancies are not carried to full term, but aborted often in unhygienic conditions leading to serious consequences. It is estimated that worldwide about 46 million pregnancies ( 22 percent of the total pregnancies and 61 percent of the unplanned/unintended pregnancies) are aborted. It is also estimated that among the total pregnancies each year in South and South-East Asia, about one-third are unplanned or unintended. For instance, 30 percent in Bangladesh, 21 percent in India, 35 percent in Nepal and 35 percent in Pakistan are unplanned pregnancies. While most of the unplanned pregnancies in developed countries occur outside the marital union (83 percent in USA) (PRCH and AGI 2003), in South and South-East Asia, it is mostly within marriage or in a stable family life. The reasons for such huge number of unplanned pregnancies in South and South-East Asia include low contraceptive use, method failure (both users' and technological faults), and high unmet need for contraceptives. "Unmet need" means that women want to limit or space future pregnancies but are not using a contraceptive method or have no access to the method.

According to an estimate, the increasing number in the total population of South and

Table 1: Fertility Trend in Selected Countries

\begin{tabular}{|l|cr|}
\hline \multicolumn{1}{|c|}{ Country } & \multicolumn{2}{|c|}{ Total fertility } \\
\cline { 2 - 3 } & $1960-70$ & 2000 \\
\hline Bangladesh & 6.3 & 3.3 \\
Bhutan & - & 4.7 \\
India & 5.0 & 2.8 \\
Nepal & 5.1 & 4.1 \\
Pakistan & - & 4.8 \\
Thailand & 6.4 & 1.7 \\
Myanmar & - & 3.1 \\
Sri Lanka & 5.0 & 2.0 \\
Maldives & - & 3.7 \\
Indonesia & 5.6 & 2.6 \\
\hline
\end{tabular}

Source: PRB 2004 and BDHS 2005

South-East Asia in each year could be reduced by one-third if all unplanned or unintended births could be avoided. For example, it is 
estimated that if all unplanned births were avoided, the fertility rate in Bangladesh would fall from 3.3 to the replacement level of 2.2 children per women (NIPORT, Mitra and Associates, and ORC Macro 2004).

\section{Population and Fertility in South and South-East Asia}

A projection of the world population shows that while the populations of the most developed countries will decrease in 2050, it will increase in the developing countries. Developing countries in Africa and Asia will account for 90 percent of the increase (PRB 2004). It is estimated that about one-third of the world's population (2,135 million) live in South and South-East Asia (PRB 2004).

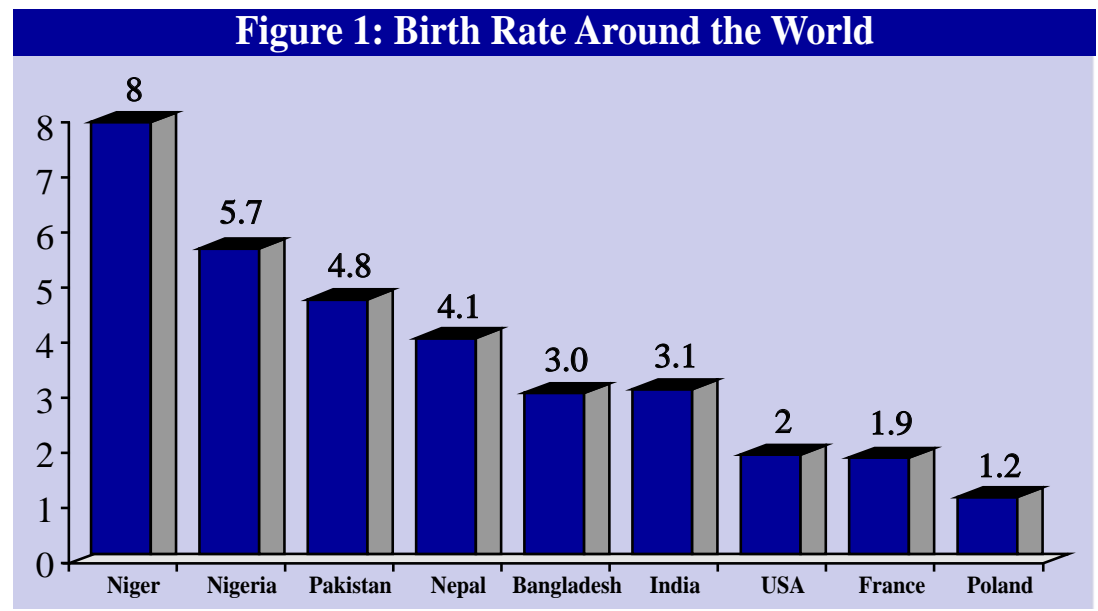

Source: PRB 2004

While in Europe, the average birth rate has fallen below two children, in some countries of Africa and Middle East, women still have six to eight children. Although most of the South and South-East Asian countries have achieved a steep decline in fertility over the last three-four decades (Table 1), an estimate reveals that populations in these countries will continue to grow over the next several decades as well and will have population almost double of what they presently have (PRB 2004). Figure 1 gives a comparative picture of birth rate in the developed world and selected large South Asian and African countries.

\section{Contraceptive Use}

Contraceptives are now being widely used in developing countries to avoid unwanted pregnancy. However, many countries are staying far 
behind the world prevalence level. Even within the region there is wide variation in the level of contraceptive use. About 60 percent of the women and men around the world are using modern contraceptive methods (PRB 2004). While more than 80 percent of women aged 15-49 living within stable relationship in developed countries use contraceptives, only about 21 percent in the

Table 2: Prevalence of Contraceptive Use and Unmet Need in Selected Countries

\begin{tabular}{|l|c|c|c|}
\hline \multirow{2}{*}{ Country } & \multicolumn{2}{|c|}{ Contraceptive use } & Unmet need \\
\cline { 2 - 3 } & $\begin{array}{c}\text { All } \\
\text { methods }\end{array}$ & $\begin{array}{c}\text { Modern } \\
\text { methods }\end{array}$ & \\
\hline Bangladesh & 58 & 43 & 15 \\
\hline Bhutan & - & 31 & - \\
\hline India & 48 & 43 & 16 \\
\hline Nepal & 39 & 35 & 28 \\
\hline Pakistan & 28 & 20 & 32 \\
\hline Thailand & 72 & 70 & 23 \\
\hline Myanmar & 33 & 28 & - \\
\hline Sri Lanka & 66 & 44 & 25 \\
\hline Maldives & 42 & 32 & - \\
\hline Indonesia & 60 & 57 & 9 \\
\hline
\end{tabular}

Source: PRB 2004 and WHO/SEARO 2002a case of Africa and 51 percent in Asia do so.

Contraceptive methods, even the most effective in preventing pregnancy, may fail for a variety of reasons related to the technologies themselves and/or due to the way they are used. It is estimated that between 8 to 30 million pregnancies each year result from contraceptive failure either due to inconsistent or incorrect use or failure of the method itself (Segal et al. 1990). In developing countries, however, errors in method use are the main cause for an overwhelming majority of unintended pregnancies. Such failure rate over a period of 12 months was much lower for methods like implants and injectables (2-4 percent) compared to condom (15 percent), periodic abstinence ( 22 percent) and withdrawal (26 percent) (Haishan et al. 1999).

The unmet need for family planning in South and South-East Asia is presented in Table 2. It shows that a considerable number of women in South and South-East Asia have the desire to use family planning but they do not have the scope to use or lack resources to do so. Unmet need for family planning method in South and South-East Asia ranges from a low 9 percent for Indonesia to as high as 32 percent for Pakistan (WHO/SEARO 2002b). For many of these countries in South and South- 
East Asia, if "unmet need" could be met, the fertility rate in each country could be drastically brought down to the replacement level or to a level that is reasonable.

\section{The Extent and Causes of Maternal Mortality}

Each year worldwide, more than 20 million women experience ill health as a result of pregnancy (WHO/SEARO 2001). Many of these pregnant women experience permanent disabilities and/or deaths due to pregnancy and delivery related complications. According to WHO estimates about 529,000 women die annually from pregnancy-related causes worldwide (WHO/UNICEF/UNFPA 2004). Ninety percent of these deaths occur in less developed countries (WHO 2004). For every woman who dies, approximately 30 more suffer injury, infection or disability during pregnancy or childbirth, averaging approximately 15 million a year.

Eighty percent of the pregnant women die due to direct causes of pregnancy (Figure 2). The indirect causes (Malaria, anemia and

\section{Figure 2: Causes of Maternal Deaths Worldwide}

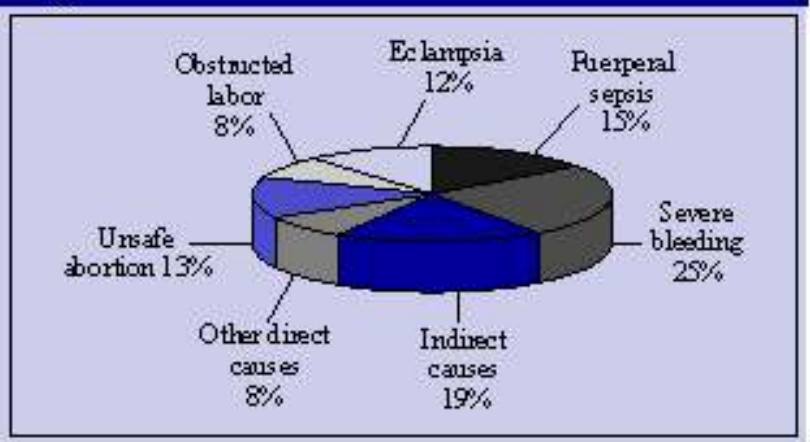

Other direct causes: Ectopic pregnancy, emboliom, and anesthesia Indirect causes: Malaria, anemia and heart diseases Soure: WHOSEAFO 2001 heart diseases) constitute about the remaining 20 percent of the maternal deaths (WHO/SEARO 2001). Studies have shown that abortion-related complications account for ne a r ly 13 percent of the

maternal deaths in the world (Figure 2). In the developing world, deaths due to abortion and its related complications is as high as 23 percent. (WHO/SEARO 2001 and PRB 2004). The wide variation in the level of maternal mortality in South Asia and East Asia is reflected in Table 3. For comparison, Maternal Mortality Rate (MMR) of selected developing countries is also given. 
One of the important and vulnerable subgroup of pregnant women is married and unmarried adolescents. A pregnant adolescent (10-19 years old) is two to five times more likely to die of pregnancy related

Table 3: Estimates of Number of Maternal Deaths, Lifetime Risk and Maternal Mortality Ratio by MDG Regions, 2000

\begin{tabular}{|l|c|c|c|}
\hline \multicolumn{1}{|c|}{ MDG region } & $\begin{array}{c}\text { No of } \\
\text { maternal deaths }\end{array}$ & $\begin{array}{c}\text { Lifetime risk of } \\
\text { maternal death } \\
\text { One in: }\end{array}$ & $\begin{array}{c}\text { MMR } \\
\text { (deaths/100,000 } \\
\text { live births) }\end{array}$ \\
\hline World & 529,000 & 74 & 400 \\
\hline Developed regions* & 2,500 & 2,800 & 20 \\
\hline Europe & 1,700 & 2,400 & 24 \\
\hline Developing regions & 527,000 & 61 & 440 \\
\hline Africa & 251,000 & 20 & 830 \\
\hline $\begin{array}{l}\text { Latin America and } \\
\text { the Caribbean }\end{array}$ & 22,000 & 160 & 190 \\
\hline Asia & 253,000 & 94 & 330 \\
\hline Oceania & 530 & 83 & 240 \\
\hline
\end{tabular}

* In addition to Europe, includes Canada, USA, Japan, Australia and New Zealand which are excluded from the regional total

Source: WHO/UNICEF/UNFPA 2004

complications than a woman of 20 to 25 years of age (WHO/SEARO 2002a). Poor physical development, lack of access to essential reproductive health care and pregnancy termination are important reasons contributed to the maternal deaths of adolescent girls. In some countries of South and South-East Asia such as India and Bangladesh, 40-50 percent of the adolescents are married and become pregnant before they reach age 20 . All these adolescents carry a high risk of pregnancy and are vulnerable to face severe complications (WHO 1997).

\section{Box 1: Abortion and Maternal Mortality} The Global Scenario

- Over half a million women die annually from pregnancy-related complications.

- The leading cause of maternal death is unsafe abortion.

- Out of every 400 women who undergo an unsafe abortion, 1 woman dies.

- Out of every 20 unsafe abortions, 19 take place in less developed countries.

- About 13 percent of all maternal deaths in the world are abortion-related.

Source: PRB 1994

Although contraceptive use is increasing and birth rate is decreasing, maternal mortality ratio (maternal deaths per 1,000 live births) has declined only marginally. Unwanted pregnancy is one of the leading 
causes of maternal mortality and morbidity. Women do not want to keep unwanted pregnancies and may use unsafe methods and/or unhygienic services to terminate their pregnancies. In addition, unwanted pregnancy increases the possibility of woman seeking menstrual regulation/abortion services. It is significant that many women who seek such services are married and in stable relationships having no objection to contraceptive use.

\section{Menstrual Regulation / Abortion Levels and Trends}

Globally, an average of 35 out of every 1,000 women of childbearing age have abortions each year (AGI 1999). In the year 2000, it is estimated that 19 million abortions were conducted in unsafe and unhygienic conditions. Thirteen percent of the maternal deaths worldwide are due to abortion-related complications. In absolute terms, every year around 68,000 women die of abortion-related complications (Table 4). According to unofficial estimates every year in India around 7 million abortions are conducted and the majority of them are unsafe and conducted under unhygienic conditions. Similarly in Bangladesh, it is estimated that about $800,000 \mathrm{MR} /$ abortions taken place every year. Among them menstrual regulation accounts for 468,299 of the pregnancies that are terminated (Singh et al. 1997). Interestingly, the majority of them are unreported, unsafe and conducted under unhygienic conditions. Although the Nepal government has recently legalized abortion, because of the lack of facilities, the majority of the abortions are conducted by untrained providers under unhygienic conditions.

\section{Table 4: Global and Regional Estimates of the Number of Unsafe Abortions and Mortality Due to Unsafe Abortion, 2000}

\begin{tabular}{|l|c|c|c|c|c|}
\hline & $\begin{array}{c}\text { Number of } \\
\text { unsafe } \\
\text { abortions } \\
\text { (Per 1,000) }\end{array}$ & $\begin{array}{c}\text { Number of } \\
\text { maternal deaths } \\
\text { due to unsafe } \\
\text { abortion }\end{array}$ & $\begin{array}{c}\text { \% of all } \\
\text { maternal } \\
\text { deaths }\end{array}$ & $\begin{array}{c}\text { Case-fatality } \\
\text { rate (\%) }\end{array}$ & $\begin{array}{c}\text { Unsafe abortion } \\
\text { deaths to } \\
\mathbf{1 0 0 , 0 0 0} \text { live } \\
\text { births }\end{array}$ \\
\hline World & 19,000 & 67,900 & 13 & 0.4 & 50 \\
\hline Developed Countries* & 500 & 300 & 14 & 0.1 & 3 \\
\hline Developing Countries & 18,400 & 67,500 & 13 & 0.4 & 60 \\
\hline Africa & 4,200 & 29,800 & 12 & 0.7 & 100 \\
\hline Asia* & 10,500 & 34,000 & 13 & 0.3 & 40 \\
\hline Europe & 500 & 300 & 20 & $<0.1$ & 5 \\
\hline $\begin{array}{l}\text { Latin America and the } \\
\text { Caribbean }\end{array}$ & 3,700 & 3,700 & 17 & 0.1 & 30 \\
\hline Oceania* & 30 & $<100$ & 7 & 0.1 & 20 \\
\hline
\end{tabular}

* Japan, Australia and New Zealand have been excluded from the regional estimates, but are included in the total for developed countries.

Source: WHO 2004 
More than half of all unsafe abortions (10.5 million) are conducted in Asia. Among them, over 7 million unsafe abortions are conducted in South Asia alone (WHO 2004). This is a reflection of the high abortion incidence in the large population of reproductive age women in South Asia. The unsafe abortion rate for Asia is 13 per 1,000 women aged 15-44 years (WHO 2004). About 14 percent of the unsafe abortions in developing countries are among women under 20 years. Table 4 shows that among the total number of maternal deaths due to unsafe abortions, 50 percent are from Asia.

Despite the wide availability of modern contraceptives, an increasing number of women continue to seek abortion and/or other pregnancy termination procedures such as menstrual regulation. In South and South-East Asia, a number of abortions are conducted using traditional methods such as inserting roots that are unsafe and could have serious consequences for maternal health and even for life. Like maternal mortality, the extent of maternal morbidity in developing countries is extremely high. There are many women who have survived from severe complications of pregnancy and childbirth to suffer from lasting conditions such as fistula, uterine prolapse, and urinary incontinence.

\section{How Can These Unwanted Deaths and Morbidities be Prevented?}

Many abortion-related deaths and morbidities can be averted by:

- Promoting the use of family planning methods, so that women would go through fewer unwanted pregnancies and deliveries.

- Strengthening post-abortion services in all clinics and making it widely and easily accessible to all women in need.

- Informing women about the high risks of traditional methods of pregnancy termination.

- Introducing and informing women about emergency contraceptive pills (ECP) as a back-up support in case other family planning methods failed or is incorrectly used and the advantage if emergency contraceptive pills (ECP) is used within 3 days of unprotected intercourse. 


\section{Role of Emergency Contraception in Reproductive Health Programs}

- Although effective methods of regular contraception are easily available, many pregnancies continue to be unplanned and unwanted. These pregnancies carry a higher risk of maternal morbidity and mortality, as women often attempt to abort these pregnancies through unsafe methods and/or in unhygienic conditions. ECP gives women a second chance to prevent any unplanned or unintended pregnancy.

- Emergency contraceptive pills are needed because no contraceptive is 100 percent reliable. Moreover, not everyone uses a contraceptive method perfectly each time they have intercourse. Emergency contraceptive pills offer women the chance to avoid unwanted pregnancy in cases where regular contraceptive methods have failed or incorrectly used. By preventing unintended pregnancies, emergency contraception can ensure that fewer women will need to seek an abortion or menstrual regulation which will eventually result in fewer pregnancy-related maternal deaths and morbidity.

- Millions of women globally have used emergency contraceptive methods safely and effectively. A recent study in China reveals that emergency contraceptive pills can halve the number of induced abortions (UNDP/UNFPA/WHO 2001).

- By offering emergency contraceptive pills, family planning and reproductive health programs can improve the quality of reproductive health services and meet the needs of clients more effectively.

\section{Points to Remember About ECP}

- Emergency contraceptive pills are not intended for regular use. They are only for emergencies.

- Emergency contraceptive pills are not as effective as regular precoital methods of contraception such as oral contraceptive pills or condoms and should be used only in emergencies when a regular contraceptive method has failed or incorrectly used.

- It is important that women are informed in advance about the option of using emergency contraceptive pills and where they can 
get such services since ECP treatment has to be sought within a very short period of time (three days of unprotected intercourse).

- Providing women with a supply of emergency contraceptive pills at the time of a regular contraceptive visit (advance supply) is one way of ensuring that they are equipped to protect themselves from an unwanted pregnancy in the event of unprotected intercourse or contraceptive failure. 
SESSION 2

Emergency Contraception and Emergency Contraceptive Pills 


\section{Session 2}

\section{Emergency Contraception and Emergency Contraceptive Pills}

\section{Objectives}

By the end of Session 2, participants will know/be able to define and discuss:

- Emergency contraception and emergency contraceptive pills

- When emergency contraception can be used?

- Methods of emergency contraception

- How emergency contraceptive pills work?

- The indications and contraindications of emergency contraceptive pills

- The characteristics of emergency contraceptive pills

- The suggested regimen for emergency contraceptive pills

- How emergency contraceptive pills should be taken?

- How the three-day interval should be calculated?

- The effectiveness of emergency contraceptive pills

- Whether emergency contraceptive pills are effective as a regular contraceptive method?

- The side effects of emergency contraceptive pills and their management

\section{Methods/Presenting the Session}

The following methods should be used:

a. An overhead projector for the transparencies

b. An informal discussion and question-answer should follow each session where participants can clarify their doubts

\section{Time Needed for Session 2}

Presentation: 60 minutes

Discussion and question - answer: 60 minutes 


\section{Emergency Contraception and Emergency Contraceptive Pills}

\section{What is Emergency Contraception and Emergency Contraceptive Pills?}

Emergency contraception (EC) refers to contraceptive methods that can be used by women to prevent an unwanted pregnancy in the first few days after unprotected intercourse or contraceptive accident such as leakage/slippage of condom. Emergency contraception should not be used as a regular family planning method but should be used only in an emergency as a back-up. Emergency contraception can be provided by emergency contraceptive pills or an Intra-Uterine Device (IUD).

Emergency contraceptive pills are a hormonal method of contraception. These pills contain the hormones found in oral contraceptive pills but in higher doses. These pills are also called "morning-after" or "post-coital" pills. However, since emergency contraceptive pills can be used up to three days after unprotected intercourse, these terms do not convey the correct timing of use. Moreover, these terms do not convey the important fact that emergency contraceptive pills are not a regular family planning method and are intended for "emergency" use only, which is why the name "emergency contraceptive pills" is more appropriate.

For centuries, women have followed a number of practices, or used a variety of devices and preparations to prevent pregnancy. These include washing the genitalia; standing up immediately after intercourse, passing urine, and walking and jumping after intercourse. These traditional methods of contraception are generally used immediately after unprotected intercourse to avoid pregnancy, although none of these methods have been found to be effective in preventing pregnancy.

In the 1960s, the first human clinical trials of hormonal emergency contraceptives were conducted, using high-dose estrogen hormone. In the 1970s, high-dose combined oral contraceptives containing ethinyl estradiol and levonorgestrel (known as the Yuzpe method) was initiated.

As is the case with developing countries, most people are not familiar with emergency contraception. Even those who have heard of the method lack accurate information on how to use emergency contraceptive pills or where to obtain them. This lack of knowledge often results in unwanted pregnancies, 
many of which lead to menstrual regulation/abortions. These, in turn, can cause a number of major health consequences for women.

\section{When Can Emergency Contraception Be Used?}

Emergency contraception can be used after unprotected intercourse if a woman does not want to become pregnant from that sexual encounter. Unprotected intercourse includes the following:

- Where a contraceptive method has not been used in voluntary sex

- When the contraceptive method has failed or the method has been used incorrectly, for instance:

- Condom breakage, slippage, or leakage

- Failure to take oral contraceptive pills on three consecutive days (combined hormone preparation)

- Delaying a contraceptive injection Depo-medroyprogesterone acetate (DMPA) by more than two weeks from the due date

- Partial or complete dislodgement of IUD

- Miscalculating the infertile period by those following periodic abstinence, or the failure to abstain from sexual intercourse during the fertile period

- Failed coitus interruptus, for instance, when ejaculation has occurred inside the vagina or on the external genitalia

- In cases of involuntary sex or sexual assault, such as rape.

\section{What Are the Methods of Emergency Contraception?}

There are two methods of emergency contraception: emergency contraceptive pills and copper-releasing IUDs.

Emergency contraceptive pills are of two types:

- Increased dose of combined oral contraceptives containing ethinyl estradiol and levonorgestrel (the Yuzpe regimen)

- High dose progestin-only pills containing levonorgestrel

The first dose of combined emergency contraceptive pills should be taken within 72 hours* of unprotected intercourse. IUDs can be inserted up to 5 days following such an episode. Although there are pills specially packed for emergency use, most brands of biphasic Oral Contraceptive Pills (OCPs) available in the national program or in the market for regular use can also be

*Recent WHO study revealed that if 1500 microgram levonorgestrel is taken together (two postinor/e-pills tablets) in a single dose the efficacy does not change and/or there is no added side effect (Hertzen et al 2002). 
used for emergency contraception. Thus, low-cost emergency contraception is already available in most countrys' family planning programs. However, the important thing is that most clients are not aware of the dose for taking these pills as emergency contraceptives, or how to switch to the regular cycle of oral contraceptive pills after using the pills as emergency contraceptives. It is critical and essential that women are told how oral contraceptive pills can be used as an emergency contraceptive and how to come back to a regular contraceptive method after using emergency contraceptive pills.

\section{How Do Emergency Contraceptive Pills Work?}

The precise mechanism of action of emergency contraceptive pills has not been clearly established. However, a number of studies have mentioned that emergency contraceptive pills can inhibit or delay ovulation. It has also been suggested that emergency contraceptive pills may:

- Prevent implantation** (by altering the inner lining of uterus (endrometrium), made unsuitable for implantation)

- Prevent fertilization

- Prevent transport of the sperm and ovum

Which mechanism is active in a particular case depends on the time of the menstrual cycle when emergency contraceptive pills are used.

Emergency contraceptive pills do not interrupt or abort an established pregnancy. They can only help prevent an unwanted pregnancy. Once implantation (pregnancy) has occurred, emergency contraceptive pills are not any more effective. Emergency contraceptive pills, thus, do not cause any form of abortion or bring about menstrual bleeding.

\section{What are the Indications and Contraindications of Emergency Contraceptive Pills?}

The absolute indication of emergency contraceptive pills is after unprotected intercourse if the woman does not want to become pregnant. Unprotected intercourse can be explained as a situation when no contraceptive has been used pre-coitally, or the method used for contraception was not used correctly or assumed that the method used for contraception was not used correctly or doubts that the method used may fail to prevent pregnancy. In these situations, women may take emergency contraceptive pills to prevent an unwanted pregnancy.

\footnotetext{
** Recent Population Council study shows that ECP does not have any effect on post-fertilization process, ECP does not prevent implantation (Population Council 2005).
} 
The use of emergency contraceptive pills is not contraindicated unless the woman is already pregnant or there is a realistic suspicion of pregnancy. This is not because emergency contraceptive pills will harm the fetus but because they will not be effective, hence unnecessary.

There are no other known medical contraindications to the use of emergency contraceptive pills. The dose of hormones used in emergency contraception is relatively small and the pills are used for a short period of time, so that the contraindications associated with regular use of combined oral contraceptives and progestin-only pills do not apply to emergency contraceptive pills.

\section{What are the Characteristics of Emergency Contraceptive Pills?}

Emergency contraceptive pills are:

- Safe and effective.

- Easy to use and widely available.

- First dose of emergency contraceptive pills must be taken within 72 hours of an unprotected intercourse and same dose should be repeated exactly 12 hours after the first dose.

- More effective if taken early, within 12-24 hours of unprotected sex.

- Can be taken at any time during the monthly cycle.

- Aphysical examination is not required.

- Can be given without a prescription depending on the medical regulations of the country.

- Can be given to women who have not taken regular oral contraceptive pills for medical reasons, such as a history of heart disease, migraine, and liver problems.

- Not recommended as a regular method.

- Do not prevent STI and HIV/AIDS.

\section{What is the Suggested Regimen for Emergency Contraceptive Pills?}

Several types of available biphasic oral contraceptive pills can be used as emergency contraceptive pills. However, irrespective of which pill is taken, the first dose must be taken within 72 hours of unprotected intercourse (earlier is better) and the second dose exactly 12 hours after the first dose.

The number of pills to be taken in each dose depends on the formulation of the contraceptive pills. Two formulations are available: combined oral pills and progestin-only pills. 


\section{Combined Oral Pills}

There are two types of combined oral pills:

- Standard/high-dose pills

These contain 50 micrograms or more of ethinyl estradiol and 250 micrograms of levonorgestrel, or 500 micrograms of dl-norgestrel.

- Low-dose pills

These contain 30-35 micrograms of ethinyl estradiol and 150 micrograms of levonorgestrel, or 300 micrograms of dl-norgestrel.

Irrespective of whether standard/high dose pills or low dose pills are taken, each dose should contain at least $0.1 \mathrm{mg}$ (100 micrograms) of ethinyl estradiol and $0.5 \mathrm{mg}$ (500 micrograms) of levonorgestrel to be effective as an emergency contraceptive. Table 5 shows a list of few oral contraceptive pills available in Bangladesh, India and Nepal and the dosage for using them for emergency contraception.

\section{Progestin-Only Pills}

Pills containing only progestin hormone are an alternative to combined oral contraceptive pills. Progestin pills are more effective and are associated with fewer side effects than combined emergency contraceptive pills. However, each dose should contain at least $0.75 \mathrm{mg}$ ( 750 micrograms) of levonorgestrel (a derivative of the progestin hormone). Like combined oral pills, the first dose of

\begin{tabular}{|l|l|l|}
\hline \multicolumn{1}{|c|}{ Table 5: What is the Recommended Dose of Regular } \\
Contraceptive Pills for Use as Emergency Contraception?
\end{tabular}

* In 28 day packs, only the first 21 pills can be used. 
progestin pills should be taken as soon as possible but within 72 hours after unprotected sex. The second dose should be taken exactly 12 hours after the first dose. One pill should be taken in each dose.

\section{How Should Emergency Contraceptive Pills be Taken?}

Like other tablets, emergency contraceptive pills should be swallowed with water. They should be taken preferably after a meal as they sometimes cause irritability of the stomach. The first dose should be timed so that the woman does not have to wake up in the middle of the night for the next dose (for example, the first dose could be taken at $8 \mathrm{a} . \mathrm{m}$. and the second dose at $8 \mathrm{p} . \mathrm{m}$.). It must be remembered, however, that any delay in starting treatment could decrease the efficacy of emergency contraceptive pills.

\section{How Should the Three-Days (72 hours) Interval be Calculated?}

To date, most studies have only examined the effectiveness of emergency contraceptive pills after a single penetrative sexual act. However, it is possible that couples may have multiple sexual encounters prior to starting a course of emergency contraceptive pills. The calculation of 72 hours or 3 days should start from the first unprotected penetrative vaginal intercourse the woman has had during that particular menstrual cycle. There is no evidence that emergency contraceptive pills can work against unprotected sexual intercourse before or after this ( 72 hours) period, or during the period when the woman is taking emergency contraceptive pills. However, it is possible that emergency contraceptive pills may work against multiple intercourses that have occurred within the 72-hour time period, but there is no study available to support this important event.

\section{How Effective are Emergency Contraceptive Pills?}

Emergency contraceptive pills are fairly effective in preventing pregnancy from unprotected sexual intercourse. However, it is important to recognize that not every woman will become pregnant after an unprotected intercourse even if she does not take any emergency contraceptive pills. Moreover, it is impossible to predict correctly who would become pregnant after an unprotected intercourse. Indeed, every woman has an equal chance of becoming pregnant after an unprotected intercourse. 
It is estimated that if 100 women have unprotected sexual intercourse during the second or third week of their menstrual cycle, 8 would become pregnant.

- If the same 100 women use combined oral pills as ECPs, instead of 8 women only 2 would become pregnant.

- If the same 100 women used progestin-only ECPs, instead of 8 women only 1 would become pregnant.

These estimates suggest that the use of emergency contraceptive pills could reduce the probability of becoming pregnant from unprotected sexual intercourse by roughly 75 percent in the case of combined oral contraceptive pills, and 85 percent in the case of progestin-only pills.

It should also be mentioned that even if emergency contraceptive pills are correctly used, a few women (15-25 percent) may become pregnant. Taking the results of the studies with high-dose oral contraceptives (which are similar to emergency contraceptive pills) into account, experts believe there is no harm to a pregnant woman or fetus if emergency contraceptive pills have failed or inadvertently used during early pregnancy. Two factors influence the efficacy of emergency contraceptive pills:

- The time gap between unprotected sexual intercourse and the start of the first dose of emergency contraceptive pills

- The time in a woman's menstrual cycle when she has had unprotected sexual intercourse (whether it is in the fertile period)

Treatment with emergency contraceptive pills should be started as soon as possible after unprotected intercourse because the sooner a woman starts taking emergency contraceptive pills after unprotected intercourse, the more effective they are. Recent studies have indicated that efficacy declines substantially over time after intercourse. The closer the woman is to ovulation at the time of unprotected intercourse, the less likely is the method to succeed.

\section{Are Emergency Contraceptive Pills Effective as Regular Contraceptive Method?}

Emergency contraceptive pills are not effective as regular contraceptives and should be used only in emergencies. Using high-dose contraceptive pills regularly can cause a number of side effects. Moreover, it is difficult to ascertain the time of ovulation and menstrual bleeding if emergency contraceptive pills are used frequently as they delay or prevent ovulation. As ovulation could occur very soon after emergency contraceptive treatment has ended, if other methods such as condoms are not used during further unprotected intercourses, there is a high possibility that a woman may become pregnant. 
Further, as the pregnancy rate for emergency contraceptive pills is based on one-time use, it cannot be directly compared to failure rates of hormonal contraceptives used regularly, which represent the risk of failure during a oneyear period of use. In fact, if emergency contraceptive pills were to be used frequently, the failure rate during a full year of use would be much higher than for regular hormonal contraceptives.

\section{Do Emergency Contraceptive Pills Have Any Side Effects?}

Emergency contraceptive pills have some side effects, many of which are similar to what women face in the first weeks of starting oral contraceptive pills. However, these side effects generally do not last more than one to two days (or a maximum of 3 days for combined emergency contraceptive pills) after the second dose of pills.

Generally, progestin-only pills have fewer side effects as compared to combined emergency contraceptive pills. While about 50 percent of women experience nausea and 20 percent vomiting in the case of combined emergency contraceptive pills, among women who use progestin-only pills, in contrast, 20 percent experience nausea and 6 percent vomiting (WHO 1998).

Some side effects that women could experience are:

- Nausea

- Vomiting

- Headache

- Dizziness

- Fatigue

- Breast tenderness

- Menstrual problems

Nausea and vomiting are the most commonly experienced side effects. These symptoms are generally limited to three days and generally resolve within 24 hours after treatment. Other side effects are less frequently reported among users of emergency contraceptive pills. If emergency contraceptive pills are frequently used, a woman's periods may become irregular and unpredictable (Knowles and Marcia 1998).

\section{How Can Side Effects Be Managed?}

- Taking emergency contraceptive pills with food or at bedtime may help reduce nausea and vomiting. Recent study shows it may not help (CEC 2005). 
- Women may have an anti-emetic an hour before taking emergency contraceptive pills to reduce nausea and vomiting. Anti-emetics are not effective once nausea begins. Meclizine Hydrochloride (available at the pharmacy under brand names such as Pregnidoxin, Ancolan, Postafen, Antivert, etc.) is the safest drug, although other anti-emetics may be helpful. A single 25mg Meclizine Hydrochloride oral dose taken one hour before the first ECP dose reduces the chance of nausea and vomiting by about 30 percent. Women should be warned that this medicine might cause drowsiness. This can be repeated two to three times a day. Prophylactic anti-emetics are not routinely recommended because they may not help all women.

- Some clinicians recommend that if vomiting occurs within two hours of taking the first dose of emergency contraceptive pills, the dose of ECP should be repeated. In such cases, the woman should take an anti-emetic an hour before this dose of emergency contraceptive pills to prevent nausea and vomiting. If vomiting occurs after the second dose is taken, the dose need not be repeated. If the vomiting is severe, the repeated or the second dose can be used intra-vaginally.

- A few women may have irregular bleeding and spotting after treatment with emergency contraceptive pills. They should be told that this is normal and is nothing to worry about. This bleeding should not be confused with menstruation, which is the much-anticipated evidence/proof that the treatment has been successful. Clients should be told that emergency contraceptive pills do not necessarily bring on menses immediately (a common misconception among users of emergency contraceptive pills); most women will have their menstrual bleeding on time or slightly early or 2-3 days late than the expected date. However, if menstruation is delayed beyond one week, a pregnancy test should be conducted to exclude the possibility of pregnancy.

- In about 10-15 percent of women, emergency contraceptive pills change the amount, duration, and timing of the next menstrual period. These effects are usually minor and do not need any treatment.

- Side effects such as breast tenderness, headache, dizziness, and fatigue are not common and do not generally last more than 24 hours. Paracetamol or Aspirin or Ibuprofen can be safely recommended for breast tenderness and headache. 


\section{Session 3}

\section{Service Delivery Guidelines for Emergency Contraceptive Pills}

\section{Objectives}

By the end of Session 3, participants would know:

- Who can provide services for emergency contraceptive pills?

- Who is eligible for services related to emergency contraceptive pills?

- What services should providers offer?

- How services should be provided to clients who have requested for emergency contraceptive pills?

- Guidelines for providing emergency contraceptive pills to clients who have experienced method failure.

- What should be done in case emergency contraceptive pills fail and the client becomes pregnant?

\section{Methods/Presenting the Session}

The following methods should be used:

a. An overhead projector for the transparencies

b. An informal discussion and question-answer session should follow where participants can clarify their doubts

\section{Time Needed for Session 3}

Presentation: 30 minutes

Discussion and question - answer: 30 minutes 


\section{Service Delivery Guidelines for Emergency Contraceptive Pills}

\section{Who Can Provide Services for Emergency Contraceptive Pills?}

Emergency contraceptive pills can be provided safely and effectively by a variety of trained personnel as well as by clinical and non-clinical service delivery systems. Doctors, nurses, midwives, pharmacists, paramedics, family welfare assistants, health assistants, depot holders and other clinically trained personnel as well as community health workers can effectively provide such services.

To ensure that emergency contraceptive pills are correctly dispensed, all providers should be appropriately trained and should follow clear service delivery guidelines. Training must include information on indications for emergency contraceptive pills, as well as the regimen, mode of action, efficacy and failure, side effects and their management, screening of women who have requested for emergency contraceptive pills, counseling and follow-up procedures. In addition, since emergency contraceptive pills are a back-up support, training should also include information on other contraceptive methods, if necessary. Refresher training on other methods would help participants understand in which contexts emergency contraceptive pills are appropriate and how to encourage clients to go back to their regular method.

\section{To Whom Should Services for Emergency Contraceptive Pills be Provided?}

Three types of clients need to be informed and educated on emergency contraceptive pills:

- Potential contraception users (those who are not yet using any method of contraception).

- Regular family planning clients, particularly those using barrier methods (condoms), oral contraceptive pills, DMPA injections or traditional methods such as withdrawal and safe period.

- Clients who have requested for emergency contraceptive pills.

\section{What Services Should Providers Offer?}

Service providers should:

- Routinely inform women and their husbands about the availability of emergency contraceptive pills during regular family planning consultations. 
- Distribute material on emergency contraceptive pills to create awareness among potential clients.

- Try and provide women with a supply of emergency contraceptive pills in advance.

Whenever possible, clients requesting for short-term contraceptive methods (such as barrier methods, oral contraceptive pills, DMPA injections or traditional methods) should be given information and services for emergency contraceptive pills. Clients requesting for long-term and permanent methods need not be provided such information and services. Clients who are interested in learning about other methods of contraception when they visit for emergency contraceptive pills should also be provided information and supplies.

\section{How Services Should be Provided to Clients Who Have Requested for Emergency Contraceptive Pills?}

Following awareness raising, women and men may seek services for emergency contraceptive pills. Service providers should address requests for emergency contraceptive services from both men and women. Service providers should remember that sexual assault is an important indication for emergency contraceptive pills. In such cases, the victim needs counseling, and legal and long-term emotional support. These women also need to be screened and treated for STIs/AIDS. These services should be provided according to the laws of the country. Service providers must follow the following guidelines when dealing with clients who have requested for emergency contraceptive pills.

\section{a. Ask and assess}

- Date of Last Menstrual Period (LMP) (because she may be already pregnant),

- Length of the woman's normal menstrual cycle (to assess whether it is normal),

- The time of all unprotected or inadequately protected episodes of sexual intercourse in the current menstrual period (women may have several episodes of unprotected intercourse in a given menstrual cycle),

- The number of hours since the first episode of unprotected intercourse in that cycle (to know whether within 72 hours time limit or not).

When a client asks for emergency contraceptive services, the first step is to assess whether emergency contraceptive pills are appropriate for her. In some cases, the client may be seeking treatment too late or may already be pregnant.

- If intercourse has occurred within the previous 72 hours ( 3 days) and the client is not breast-feeding, then either combined emergency contraceptive pills or 
progestin pills can be prescribed and provided.

- If the client is breast-feeding, then progestin pills are more appropriate as they do not affect the quantity or the quality of breast milk. However, there is no evidence that combined emergency contraceptive pills decrease the quantity and quality of breast milk as the length of exposure of hormone is very short.

- If the recommended time limit of 72 hours for using emergency contraceptive pills has been crossed but the woman is still within the 120-hour period, then she should be asked to use an IUD and referred to an appropriate health center.

- If the woman has crossed the 120 -hour time limit or if there is a possibility that she may be pregnant, she should be asked to wait until the next menses starts. A pregnancy test can be conducted to confirm her pregnancy status. Other health assessments such as a pelvic exam are not recommended. Sample screening questions are presented below.

\section{Sample screening questions}

1. Have you had unprotected intercourse during the last three days?

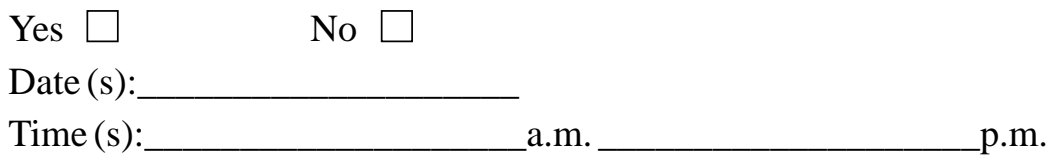

2. Which was the first day of your last menstrual period?

Date:

Is this less than 4 weeks ago? Yes $\square \quad$ No $\square$

3. Was this period normal in terms of both length and duration? Yes $\square$ No $\square$

If the response to all three questions is YES, emergency contraceptive pills can be prescribed. If the response to any of these questions is $\mathrm{NO}$, or the provider feels that the client's sexual history is inaccurate, the client should have a pregnancy test. If the pregnancy test is negative, emergency contraceptive pills may be prescribed. However, the client should be informed that it may be too early to detect pregnancy and, if the woman is already pregnant, emergency contraceptive pills will neither prevent the pregnancy nor harm the fetus.

\section{b) Inform and explain}

Clients should be informed about various aspects of emergency contraceptive pills, such as the correct dosage, how they work to prevent a pregnancy, their failure rate, how effective they are, why they should be taken as soon as possible after unprotected intercourse, possible side effects and their management. Clients should also be informed that the next period may be early or delayed by a few days but it must be within one week of the expected date. 


\section{c) Remind the client}

Clients should be reminded about the side effects of emergency contraceptive pills and how to manage them. They should also be told when to come back for a follow-up visit, if required. Generally, follow-up visits for emergency contraceptive pills are not necessary but a client should return to the clinic if her period is delayed by more than a week or if she has had very light (in terms of color) menstruation. Very light menstruation may be a sign of ectopic pregnancy, especially if it is accompanied by severe lower abdominal pain and faintness. However, there is no evidence that emergency contraceptive pills increase the chance of an ectopic pregnancy.

\section{d) Use missed opportunity}

When a client asks for emergency contraceptive pills, the service provider should take the opportunity to inform her about regular methods of contraception as well. If the client is seeking treatment after method failure, she should be told how to use the method correctly and consistently. If the client has not used any contraceptive method, she should be informed about the available methods for contraception and the advantages of regular contraception. If the client visits for other family planning services, the provider should use the opportunity to talk about emergency contraceptive pills. It is not suggested that emergency contraceptive treatment is discussed with women who are seeking long-term or permanent contraceptive methods.

\section{e) Initiating or resuming regular contraception (encourage the client to resume regular contraception)}

It is crucial that clients do not rely entirely on emergency contraceptive pills for regular contraception. Clients must be encouraged to continue using regular and permanent methods so that the country's total fertility rate decreases. Service providers must try and encourage users of emergency contraceptive pills to return to a regular contraceptive method (informed) or to the method that was being used earlier, whichever is preferred.

A client can choose a method from a number of regular contraceptive options after using emergency contraceptive pills:

- Condoms or oral contraceptive pills, which can be used immediately after the second dose of emergency contraceptive pills is taken.

- Injectables, IUDs, Implants (Norplant), sterilization or natural/traditional methods, which should be started after assessing the next menstruation. Some providers suggest that oral contraceptive pills should also be started after assessing the next menstruation. 
Options for regular contraception after the use of emergency contraceptive pills and when and how to start them are presented in Figure 3.

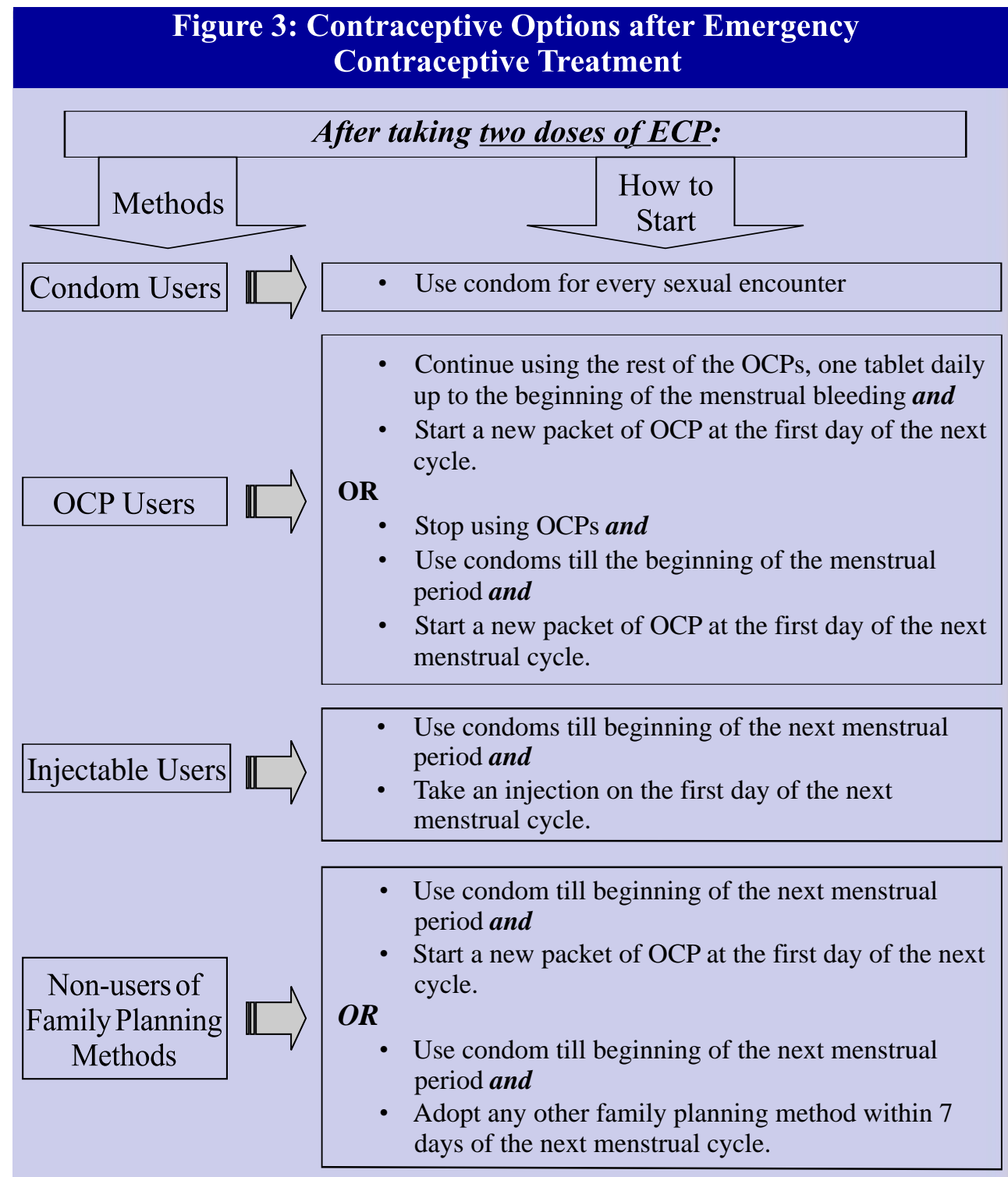

\section{What Should Be Done in Case of Regular Contraceptive Method Failure?}

\section{If a client misses an oral contraceptive pill for three consecutive days:}

The National Family Planning Program has set guidelines on what should be done if 1 , 2, or 3 oral contraceptive pills are missed consecutively. Only low-dose pills are 
available in Bangladesh, India, and Nepal through the National Family Planning program. The social marketing companies are also marketing low-dose oral contraceptive pills. The current national guidelines should be followed for missing 1 and 2 pills. The national guidelines have recommended that in case three consecutive days pills are not taken:

- The pills should be discontinued and discarded as the contraceptive effect of the pills would be lost. Moreover, many women may start withdrawal bleeding and

- The client should use condom during the rest of the cycle, if needed and

- The client should start a new pill packet from the first day of the beginning of the next cycle.

\section{The revised guidelines are:}

Some women who have missed three consecutive pills may start withdrawal bleeding. These women should follow the earlier guidelines. Women who have not started withdrawal bleeding are potential clients for emergency contraceptive pills. They have several options:

\section{Those who have had intercourse should:}

- Take two doses of emergency contraceptive pills and

- After taking both doses, they should continue to take the rest of the oral contraceptive pills, one tablet daily till the next menstrual cycle starts (this will help the woman maintain the length of her menstrual cycle) and

- Use a condom for any further intercourse as the contraceptive effect of the pills is lost once two or more pills of low-dose pills have been missed consecutively and

- Start a new packet of oral contraceptive pills on the first day of the next cycle.

\section{Those who have not had intercourse should:}

- Stop using oral contraceptive pills and

- Use condoms (if any intercourse happens) till the next menstrual period begins and

- Start a new packet of oral contraceptive pills on the first day of the next cycle.

(Note: Those women who were using progesterone-only pills should be advised to take the pills continuously at the same time each day. If one or more pills are missed, she can take ECP. She should also continue to take oral contraceptive pills as usual and must use condom for subsequent intercourses). 


\section{If the condom burst or leaked during intercourse}

\section{The client should:}

- Take two doses of emergency contraceptive pills and

- After taking two doses, use condoms consistently and correctly till the beginning of the next menstrual period and

- Start using a condom again from the beginning of the next menstrual cycle (if the client wants to rely on condoms) or

- Start a new packet of oral contraceptive pills after the second dose of emergency contraceptive pills or shift to other methods according to national guidelines (if the client wants to shift).

\section{If the client misses the due date of a contraceptive injection}

A contraceptive injection can be taken 14 days prior to or after the recommended date. If a woman crosses this 14-day period and seeks treatment within 72 hours of intercourse, she should be treated with emergency contraceptive pills. If she has not had intercourse she can be given a contraceptive injection.

Women who have missed the recommended date for the injection and seek treatment after having intercourse should:

- Take two doses of emergency contraceptive pills and

- After taking both doses, use condoms till the next menstrual cycle begins and

- Take an injection on the first day of the next menstrual cycle.

Some women who are taking contraceptive injections do not experience menstrual bleeding for many months. Service providers are often unsure about what should be done in case a woman has missed the due date for an injection and seeks treatment after intercourse. In such situations, it is advisable that after treatment with emergency contraceptive pills and before a subsequent injection is administered, the service provider should confirm that the client is not pregnant. A simple urine test can be performed to test for pregnancy.

\section{What Should Be Done if Emergency Contraceptive Pills Fail and the Client Becomes Pregnant?}

It is estimated that about 15-25 percent (as explained in page 27) of the women who use emergency contraceptive pills may become pregnant even though they use the pills correctly. The possibility of "failure" must be mentioned when emergency contraceptive pills are dispensed, otherwise the service provider may be blamed if the 
pills are ineffective. This may have an adverse impact on the ongoing National Family Planning Program.

If the client has used emergency contraceptive pills and has not menstruated for a week or more after the expected date, she may be pregnant. A pregnancy test should be conducted to confirm the pregnancy. If the client is pregnant, she should be told about the available options, and asked to choose the most appropriate option for her situation. If the client would like to continue with the pregnancy, she should be reassured that emergency contraceptive pills do not harm the fetus. 


\section{SESSION 4}

Counseling on Emergency Contraceptive Pills and Frequently Asked Questions 


\section{Session 4}

\section{Counseling on Emergency Contraceptive Pills}

\section{Objectives}

By the end of Session 4, participants will know:

- What and how to counsel on emergency contraceptive pills?

- The answers to frequently asked questions on emergency contraceptive pills.

\section{Methods/Presenting the Session}

The following methods should be used:

a. Presentation of the transparencies with an overhead projector

b. An informal discussion and question-answer session

\section{Time Needed for Session 4}

Presentation: 30 minutes

Discussion and question - answer: 30 minutes 


\section{Counseling on Emergency Contraceptive Pills}

\section{Whom to Counsel and About What?}

Counseling is an integral and essential part of family planning service delivery. Family planning counseling is a face-to-face communication in which one person helps another to make decisions and act upon them by providing relevant information. Any family planning provider, at any level and at any time, can help a client to make these decisions.

Counseling on emergency contraceptive pills is no different from counseling on other family planning methods. As it is a relatively new back-up method, and most clients do not know much about it, it is important that potential clients are properly informed.

All clients do not need counseling on every method at the time of a contraceptive consultation. Information must be tailored to suit the client's needs. As emergency contraceptive pills are a relatively new back-up support, it is essential that clients are provided information and services (i.e., the supply of pills) on this method during counseling on other contraceptive methods. Clients who are interested in learning about other methods when they visit for counseling on emergency contraceptive pills should be given information on these methods as well.

Three types of clients need to be educated on emergency contraceptive pills:

- Potential contraceptive users (those who are not yet using any method of family planning)

- Regular family planning clients, particularly those who use barrier methods, oral contraceptive pills, DMPA injections and traditional methods

- Clients who ask for emergency contraceptive pills.

\section{Potential contraceptive users}

It is essential that all potential clients for contraception are informed about the benefits of family planning and provided option for contraceptive methods. While talking about all other contraceptive methods, there is a great opportunity for providers to inform clients about emergency contraceptive pills. Non-users of family planning methods should be informed about:

- The methods available for contraception

- Details about the family planning methods

- The scope of emergency contraceptive pills as a back-up support. 


\section{Regular family planning clients}

Users of barrier methods, DMPA injections and traditional methods must be told:

- How to use barrier methods, DMPA injections and traditional methods correctly

- When and how to use emergency contraceptive pills

- What the side effects of emergency contraceptive pills are and how these should be managed

- What contraceptive options are available after using emergency contraceptive pills

- What should be done if a woman misses her menses more than 7 days from the expected date, after having emergency contraceptive pills.

Users of oral contraceptive pills must be told in particular:

- What to do if they miss three pills

- When and how emergency contraceptive pills should be used

- What should be done with the rest of the pills in the packet

- Why condoms should be used for any further intercourse

- What should be done if the menstrual cycle is delayed by more than 7 days from the expected date and

- How to come back to using oral contraceptive pills regularly once the next menstrual cycle starts.

\section{Clients who have asked for emergency contraceptive pills}

Counseling clients who have requested for emergency contraceptive pills after unprotected intercourse is simple. Five steps should be followed:

1. Ask and assess (screening questions)

2. Inform

3. Explain

4. Remind

5. Return

Ask screening questions to assess whether woman has come within 72 hours. If the client visits within the 72 hour time period, she should be informed about the correct use of emergency contraceptive pills, how emergency contraceptive pills work, efficacy and failure, and when emergency contraceptive pills are most effective. Clients should be told NOT to take any extra pill(s) as this will NOT make them work better, and may result in more side effects. Many clients mistakenly believe that emergency contraceptive pills result in immediate menstruation. Clients should be told that emergency contraceptive pills do not result in immediate menses but will come at the expected time or few days earlier or later. 
The next step is to remind the client about the side effects of emergency contraceptive pills and how these should be managed. If the client is counseled before she takes the pills, she will find it easier to cope with the side effects. Moreover, the client needs to be told that emergency contraceptive pills are not 100 percent effective and can result in failure. The client should be reminded that emergency contraceptive pills should be used only in emergencies and not as a regular method of contraception as they are not as effective as regular contraceptives. Moreover, emergency contraceptive pills have a higher failure rate and more side effects than regular contraceptives.

Although users of emergency contraceptive pills do not require routine followup, clients should be asked to come back to the clinic if their menses is delayed by more than a week, or if the menses is too light in terms of color. Clients who would like to discuss emergency contraceptive pills in detail, or would like to talk about future contraception, or has any other concern, should also be asked to come back.

It is crucial that the client should not rely totally on emergency contraceptive pills for her contraceptive needs. Service providers should try and encourage the client to return to a regular method or to her previous method rather than continue to use emergency contraceptive pills. There are many regular contraceptive options that a client can use after emergency contraceptive treatment, which have been listed in the service delivery guidelines. 


\section{Frequently Asked Questions About Emergency Contraceptive Pills}

Are emergency contraceptive pills safe?

YES, emergency contraceptive pills can be given even to women who cannot use oral contraceptive pills regularly, such as those with a history of hypertension, or severe migraine. This is because emergency contraceptive pills are taken for a short span of time and, consequently, will have fewer side effects than that of oral contraceptive pills. It will not have side effects that may have developed due to use of oral contraceptives for long periods.

\section{How will emergency contraceptive pills affect a woman's menses?}

Emergency contraceptive pills have no significant impact on a woman's menses. Only 10-15 percent of the women who use emergency contraceptive pills will have menstrual problems. A woman's menses will be at about the expected time, or at most a week early or late (usually 2-3 days). In a few cases, menstrual flow might be heavier, lighter or more spotty than usual.

Will emergency contraceptive pills protect a woman from future unprotected intercourse?

NO. Emergency contraceptive pills do not protect a woman from any future unprotected intercourse.

Will emergency contraceptive pills harm an existing pregnancy or a pregnancy caused by the failure of emergency contraceptive pills?

NO. Available studies show that emergency contraceptive pills do not have an adverse effect on pregnancy.

Can emergency contraceptive pills be taken if there is problem in the leg (such as varicose veins)?

YES. As the dose of hormones in emergency contraceptive pills is relatively low, the short exposure to estrogen and/or progestin does not appear to alter blood-clotting mechanisms, as against combined oral contraceptives, which are used over a longer period.

How many times can one take emergency contraceptive pills in a month?

Emergency contraceptive pills are not intended for repeated use. These pills should be used only as an emergency method for back-up support. Even women who have sex only three or 
four times in a month should not use emergency contraceptive pills as a regular family planning method. Given that there is little likelihood that limited repeated use will cause harm, emergency contraceptive pills should not be denied only because a woman has used them before, even within the same menstrual cycle. All women who use emergency contraceptive pills, particularly those who use them repeatedly, should be informed that emergency contraceptive pills are less effective and have more side effects than regular contraceptives. They should also be briefed on how to avoid contraceptive failure in future.

\section{How soon after emergency contraception should a regular contraceptive be started?}

Regular contraceptive methods (such as condoms and pills) can be resumed immediately after emergency contraceptive treatment. Alternatively, clients could switch over to condoms till the start of the next menstrual cycle. Other regular contraceptives such as IUD, Norplant, etc. can be started within 7 days of the next menstrual period.

What should be done if menses is delayed by more than $\mathbf{7}$ days after using emergency contraceptive pills?

The woman should undergo a pregnancy test.

\section{Do emergency contraceptive pills increase the risk of an ectopic pregnancy?}

NO. Emergency contraceptive pills neither prevent nor increase the chance of an ectopic pregnancy (a pregnancy that develops outside the uterus but inside the fallopian tube/abdomen).

\section{Is emergency contraception the same as abortion?}

NO. Emergency contraception and abortion are entirely different. Emergency contraceptives only prevent pregnancy from unprotected sex by preventing or delaying ovulation. In an abortion, a fertilized fetus is removed.

\section{Are emergency contraceptive pills and RU 486 same?}

NO. Emergency contraceptive pills are used to prevent pregnancy. Mifepristone or RU 486 is abortive and is used to abort an established early pregnancy. However, RU 486 can also be used as emergency contraceptive.

\section{What are the types and brands of pills one can use as emergency contraceptive pills?}

The types of pills that can be used as an emergency contraceptive are given in Table 5 in section 2. See Table for answers specific to your country. 
Should combined emergency contraceptive pills be given to a woman who does not take regular oral contraceptive pills for any of the following reasons:

\section{Condition}

Smoker and over 35 years

Diabetic with vascular disease

History of severe migraine (headache)

History of venous thromboembolism

Benign/malignant tumor
Can be given emergency contraceptive pills

Yes

Yes

Yes

Yes

Yes

If a woman vomits within two hours of taking a dose of emergency contraceptive pills, what should she do?

She should repeat the first dose of emergency contraceptive pills. An anti-emetic can be taken one hour before the second dose to reduce nausea.

\section{Do women need to use emergency contraceptive pills during the "infertile period"?}

Studies have shown that intercourse can result in fertilization only during a five-seven-day period around the time of ovulation (Wilcox et al. 1995). Theoretically, emergency contraceptive pills are not needed if unprotected intercourse occurs at other times of the cycle because the possibility of becoming pregnant even without emergency contraceptive pills would be negligible. However, in practice, and for the family planning program, it is often difficult to determine with certainty whether a specific act of intercourse occurred on a fertile or infertile day of the cycle. This is particularly true for illiterate women. Therefore, emergency contraceptive pills should be provided if unprotected intercourse has taken place on any day of the cycle (within 72 hours) and the client feels that she is at risk of becoming pregnant. In situations where unprotected intercourse is unlikely to result in pregnancy, the client's anxiety level, the availability of the program and the resources of the client should be taken into account when taking a decision.

\section{Can women use emergency contraceptive pills before intercourse?}

NO. Clients should be discouraged from using emergency contraceptive pills before intercourse. No data are available on how long the contraceptive effect of emergency contraceptive pills persists after the pills have been taken. Presumably emergency contraceptive pills taken immediately before intercourse are as effective as pills taken immediately afterwards. However, if a woman has the opportunity to plan to use a contraceptive method before intercourse, a regular method other than emergency contraceptive pills, such as condoms, is recommended. 
Can emergency contraceptive pills be used after more than one unprotected act of intercourse within 72 hours?

Emergency contraceptive pills should not be withheld if the client has had more than one unprotected act of intercourse within 72 hours, unless she is known to be already pregnant. However, clients should be informed that, as the interval between the earliest unprotected sexual act(s) and the use of emergency contraceptive pills lengthens, the efficacy of emergency contraceptive pills will be lower. Clients should be encouraged to use emergency contraceptive pills as soon as possible after unprotected intercourse rather than wait until they have had a series of episodes of unprotected intercourse. Only one regimen for emergency contraceptive pills should be given at a time, regardless of the number of prior episodes of unprotected intercourse.

\section{Can emergency contraceptive pills be used more than 72 hours after unprotected intercourse(s)?}

Studies show that the efficacy of treatment declines with time, so that there is declining effectiveness as the 72 hours progress. However, experts suggest that emergency contraceptive pills probably retain some limited efficacy even after that period (Ellertson et al. 2000; Piaggio et al. 1999). Since emergency contraceptive pills pose no danger either to the woman or to the embryo, it is reasonable to provide women emergency contraceptive pills even after 72 hours even if emergency contraceptive pills fail. However, the client should be informed about the possibility of pregnancy, if the method fails or if she is already pregnant.

\section{Can emergency contraceptive pills be taken when a woman is breastfeeding?}

A woman who is less than six months postpartum, exclusively breastfeeding and who has not had a menstrual period since delivery is unlikely to ovulate and, therefore, may not need emergency contraceptive pills. However, a woman who is providing supplementary feeding to her infant or who has had menses since delivery, even a single time, may be at risk of pregnancy. A single treatment with combined emergency contraceptive pills is unlikely to have a serious effect on the quantity and quality of milk she produces. Some hormones may get absorbed into the breast milk but they are unlikely to affect the infant adversely. The amount of hormone that goes into the infant's body is almost same as the infant would normally take from the mother's body through breast milk. However, for women who are breastfeeding, progestin-only emergency contraceptive pills are more suitable and they do not change the quantity and quality of breast milk.

\section{Can emergency contraceptive pills be given while the status of pregnancy is unclear?}

Emergency contraceptive pills may be given when a woman's pregnancy status is unclear and a pregnancy test is not available, as there is no evidence suggesting that emergency 
contraceptive pills harm the woman or an existing pregnancy. However, a client should be informed that she might already be pregnant and, in such cases, emergency contraceptive pills will not be effective.

If knowledge of emergency contraceptive pills become widespread, could incorrect use or overuse of these pills become a problem?

Misuse is not likely. Even in countries where emergency contraceptive pills are easily available, they have not been misused. World Health Organization suggests that making emergency contraceptive pills readily available with accurate instructions through established family planning services, whether clinic, pharmacy or community based, will help to reduce any risk of incorrect use or overuse and will ensure appropriate follow-up counseling and contraceptive services.

\section{Do emergency contraceptive pills interact with other drugs?}

There is no specific data available about the interaction of emergency contraceptive pills with other drugs that the client may be taking. However, it seems reasonable that drug interactions would be similar to those with regular oral contraceptive pills. Women taking drugs that may reduce the effectiveness of oral contraceptives including but not limited to Rifampicin and certain anticonvulsant drugs should be advised that the effectiveness of emergency contraceptive pills may be reduced. In this case, she may increase the amount of hormone in each dose. 


\section{Bibliography}

Akhter H. K. 1986. "Medical Practice After Legalization of Abortion: Bangladesh. Prevention and Treatment of Contraceptive Failure." In Honor of Christopher Tietze, edited by U Landy and S S Ratnam. New York: Plenum Press.

Alan Guttmacher Institute (AGI). 1999. "Abortion Data from Reports of the Alan Guttmacher Institute." New York: AGI.

.1999. "Sharing Responsibility: Women Society and Abortion Worldwide." New York: The Alan Guttmacher Institute.

Bangladesh Bureau of Statistics. 2001. "Population Census 2001: Preliminary Report." Dhaka: Bangladesh Bureau of Statistics.

Statistics.

2000. "Statistical Pocketbook of Bangladesh." Dhaka: Bangladesh Bureau of

.1997. "Gender Statistics in Brief, 1997." Dhaka: Bangladesh Bureau of Statistics.

Center for Disease Control. 2004. "Fact Sheet: Abortion Surveillance." Atlanta: Center for Disease Control.

Consortium for Emergency Contraception.2002. "Expanding Global Access to Emergency Contraception: A Collaborative Approach to Meeting Women's Needs." Seattle: Consortium for Emergency Contraception.

. 2000. "Emergency Contraceptive Pills: Medical and Service Delivery Guidelines."

Seattle: Consortium for Emergency Contraception.

. 1996. "Emergency Contraceptive Pills: A Resources Packet for Health Care Providers and Program Managers." Seattle: Consortium for Emergency Contraception.

Cunningham F. Gary et al. 1997. "Williams Obstetrics [20th Edition]." Stamford: Appleton and Lange.

Ellertson C. et al. 2000. "Refining the Yuzpe Method of Emergency Contraception." New York: Population Council.

Family Health International. 1999. "Contraceptive Technology Updates Series." North Carolina: Family Health International.

Haishan Fu, Jacqueline E. Darroch, Taylor Haas and Nalini Ranjit. 1999. "Contraceptive Failure RaStes: New Estimates from the 1995 National Survey of Family Growth." Family Planning Perspectives, 31 (2):56-63.

Hatcher, Robert A., Ward Rinehart, Richard Blackbuurn and Judith S. Geller. 2001. "The Essential of Contraceptive Technology: A Handbook for Clinic Staff." Baltimore: Johns Hopkins School of Public Health, Population Information Program. 
Henshaw, S.K.1990. "Induced Abortion: A World Review." Family Planning Perspectives, 22: 76-89.

International Consortium for Emergency Contraception. 2004. "Emergency Contraceptive Pills: Medical and Service Delivery Guidelines."

Islam Waliur and M. Shahadat Hossain. 1997. "Reproductive Health Status in Bangladesh, 1997." Dhaka: Bangladesh Bureau of Statistics.

Kamal, H., A. Hussain, S.F. Begum, G.M. Kamal. 1993. "Prospects of Menstrual Regulation Services in Bangladesh: Results of an Operational Research." Dhaka: Bangladesh Association for Prevention of Septic Abortion (BAPSA).

Knowles, Jon and Marcia Ringel. 1998. "All About Birth Control." New York: Three Rivers Press, Pp169-170.

Ministry of Health and Family Welfare and National Integrated Population and Health Program (MHFW and NIPHP). 2000. "Contraception Manual." Dhaka: Ministry of Health and Family Welfare.

Ministry of Health and Family Welfare (MHFW). 2001. "Bangladesh National Strategy for Maternal Health." Dhaka: Ministry of Health and Family Welfare.

. 2001. "Letter. No:Pakaw-1/ECP/22/2001/248, date 31/12/2001, Ministry of Health and Family Welfare, Development 1 Branch; Government of Bangladesh." Dhaka: Ministry of Health and Family Welfare.

Nayyar, Anjali. 2000. "Emergency Contraception: Know Your Option." New Delhi, India: Population Council.

NIPORT, Mitra and Associates and Measure/DHS+ ORC-Macro Internationals Inc. 2000. "Bangladesh Demographic and Health Survey 1999-2000." Dhaka: NIPORT, Mitra and Associates and Measure/DHS+ ORC-Macro Internationals Inc.

2001. "Preliminary Report: Bangladesh Maternal Health Services and Maternal Mortality Survey 2001." Dhaka: NIPORT, Mitra and Associates and Measure/DHS+ ORCMacro Internationals Inc.

NIPORT, Mitra and Associates, and ORC Macro Inc. 2001. "Bangladesh Demographic and Health Survey." Dhaka: NIPORT, Mitra and Associates, and ORC Macro.

2004. "Bangladesh Demographic and Health Survey 2003-2004." Dhaka: NIPORT, Mitra and Associates, and ORC Macro.

NIPORT, ORC Macro, Johns Hopkins University and ICDDR,B. 2003. "Bangladesh Maternal Health Services and Maternal Mortality." Dhaka: NIPORT, ORC Macro, Johns Hopkins University and ICDDR,B

Pacific Institute for Women's Health. 2000. "A Clinician's Guide to Providing Emergency Contraceptive Pills." Los Angeles: Pacific Institute for Women's Health. 
Paul, F.A., Van Look and Felicia Stewart. 1998. "Emergency Contraception." In Robert Hatcher et al., eds, Contraceptive Technology, pp. 277-95.New York: Ardent Media.

Physician for Reproductive Choice and Health (PRCH) and Alan Guttmacher Institute (AGI). 2003. "An Overview of Abortion in the United States." New York: PRCH and AGI.

Piaggio G., H. von Herzen, D.A. Grimes and P.F.A. Van Look. 1999. "Timing of Emergency Contraception with Levonorgestrel or the Yuzpe Regimen." Lancet, 353: 721.

Planned Parenthood Federation of America. 1998. "Emergency Contraception Handbook." New York: Planned Parenthood.

Population Council 2005. "Emergency Contraception's Mode of Action Clarified" Population Briefs, vol. 11, no:2.

Population Reference Bureau. 2004. "2004 World Population Data Sheet." Washington DC: PRB.

Population Reports. Series J No. 35, 36, 48 and 7. Washington: Population Reference Bureau.

Ransom, E. I. and Nancy V. Yinger. 2002. "Making Motherhood Safer: Overcoming Obstacles on the Pathway to Care." Washington: Population Reference Bureau.

Rochat, R.W., S. Jabeen, M.J. Rosenberg, A. R. Measham, A.R. Khan, M. Obaidullah and P. Gould. 1981. "Maternal and Abortion Related Deaths in Bangladesh, 1978-79." International Journal Gynaecology Obstetrics, 19: 155-64.

Royston, E. and S. Armstrong. 1989. "Preventing Maternal Deaths." Geneva: World Health Organization.

Segal, S. J. and K. D. LaGuardia. 1990. "Termination of Pregnancy: A Global View." Balliere's Clinical Obstetric and Gynecology, 4(2): 235-247.

Singh, Susheela, Josefina V. Cabigon, Altaf Hossain, Haidary Kamal and Aurora E. Perez. 1997. "Estimating the Level of Abortion in the Philippines and Bangladesh." International Family Planning Perspectives, 23: pp100-107 \& 144.

UNDP/UNFPA/WHO/World Bank Special Programme of Research, Development and Research Training in Human Reproduction. 2001. "Use of Emergency Contraception Pills Could Halve the Induced Abortion Rate in Shanghai, China." Social Science Research Policy Briefs. Series 2. No 1.

UNFPA. 1997. "The State of World Population 2004." New York: UNFPA.

UNICEF. 1994. "Emergency Obstetric Care: Intervention for the Reduction of Maternal Mortality." Dhaka: Obstetrical and Gynaecological Society of Bangladesh.

United Nations. 1999. "World Abortion Policies." New York: United Nations, Population Division, Department of Economic and Social Affairs. 
Von Hertzen H, Piaggio G, Ding J, Chen J, Song S, Bartfai G, et al 2002. "Low Dose Mifepristone and Two Regimens of Levonorgestrel for Emergency Contraception: A WHO Multicentre Randomised Trial." Lancet,360:1803-10.

Wilcox, A.J., C.R. Weinberg and D.D. Baird. 1995. "Timing of Sexual Intercourse in Relation to Ovulation: Effects on the Probability of Conception, Survival of Pregnancy, and Sex of the Baby." New England Journal of Medicine, 333:1517-21.

World Bank. 1995. "Bangladesh: From Stabilization to Growth." Washington, D.C.: The World Bank.

World Health Organization (WHO). 2004. "Unsafe Abortion- Global and Regional Estimates of the Incidence of Unsafe Abortion and Associated Mortality in 2000." 4th edition. Geneva: World Health Organization.

.2002. "Improving Access to Quality Care in Family Planning: Medical Eligibility Criteria for Contraceptive Use." Geneva: WHO.

. 1999. "Reduction of Maternal Mortality: A Joint WHO/UNFPA/UNICEF/World Bank Statement." Geneva: WHO.

. 1998. "Emergency Contraception: A Guide for Service Delivery." Geneva: WHO.

.1997. "Maternal Health Around the World" (wall chart). Geneva: WHO.

World Health Organization/SEARO. 2002a. "Women's Health in South-East Asia." Delhi: World Health Organization/SEARO

.2002b. "Women of South-East Asia: A health profile." Regional Publications, SEARO No. 34. Delhi: World Health Organization/SEARO.

.2001. "Making Pregnancy Safer." Delhi: WHO/SEARO.

WHO/UNICEF/UNFPA. 2004. "Maternal Mortality in 2000: Estimates Developed by WHO, UNICEF and UNFPA." Geneva: Department of reproductive Health Research, WHO 


\section{ECP in the National Program}

\section{Emergency Contraceptive Pills (ECP)}

Pre-test Questionnaire

Organization: Designation:

Specialty: Age: $\square$ Female

1. Which of the following statements describe the purpose of emergency contraceptive pills (ECP) as a contraceptive method? (check one that applies)

1 ECP is used before unprotected intercourse* to avoid unwanted pregnancy

2 ECPis used after unprotected intercourse* to avoid unwanted pregnancy

8 Donot know

2. When will you say unprotected intercourses that have happened require ECP? (check all that apply)

1 One combined oral contraceptive pill was missed in a given cycle

2 Three combined oral contraceptive pills were missed in a given cycle

3 One progestin-only oral contraceptive pill was missed in a given cycle

4 Missed injection due date (also extended 14 days) and had unprotected intercourse

5 Acontraceptive method failed during use (e.g. condom leak or slip)

6 Unprotected intercourse occurred as a result of rape

7 Intercourse without any method

8 Donotknow

3. What amount of hormone, the combined oral contraceptive pill must contain (Yuzpe regimen) to be effective as emergency contraceptive pill? (check all that apply)

1 At least $0.1 \mathrm{mg}$ of ethinyl estradiol and $0.5 \mathrm{mg}$ of levonorgestrel

2 At least $0.2 \mathrm{mg}$ of ethinyl estradiol and $0.5 \mathrm{mg}$ of levonorgestrel

3 At least 100 microgram of ethinyl estradiol and 500 microgram of levonorgestrel

4 At least 200 microgram of ethinyl estradiol and 1000 microgram of levonorgestrel

8 Donot know

4. What amount of hormone the progestin-only pill regimen must contain to be effective as emergency contraceptive pill? (check all that apply)

1 At least $0.5 \mathrm{mg}$ of levonorgestrel

2 At least $1.5 \mathrm{mg}$ of levonorgestrel

3 At least $0.75 \mathrm{mg}$ of levonorgestrel

8 Donot know

*Unprotected intercourse means intercourse without any contraceptive methods or methods used incorrectly or thought that method used may not work perfectly. 
5. In what way emergency contraceptive pills work? (check all that apply)
1 It prevents ovulation
2 It prevents fertilization
3 It kills spermatozoa
4 It aborts fertilized ovum
5 It delays ovulation
7 It prevents implantation
6 It makes uterine cavity unsuitable for ovum
8 Do not know

6. ECP must be initiated within hours. (check one that apply)

1 Within 24 hours after unprotected sex

2. Within 72 hours after unprotected sex

3 Within 48 hours after unprotected sex

4 Within 96 hours after unprotected sex

8 Within 120 hours after unprotected sex

8 Do not know

7. How many doses of ECP should be taken? (check all that apply)
1 One
2 Two
3 Three
4 Four
8 Do not know

8. What is the interval between doses of ECP? (check all that apply)
16 hours
312 hours

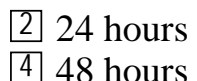
5 Not applicable
8 Do not know

9. Below is a list of statements regarding emergency contraceptive pills. Please indicate whether each statement is true or false by circling the correct answer.
a. $1 \mathrm{~T} 2 \mathrm{~F}$
ECP can be used at any time during the menstrual cycle
b. $3 \mathrm{~T} 4 \mathrm{~F}$
c. $5 \mathrm{~T} 6 \mathrm{~F}$
ECP is an abortifacient
d. $7 \mathrm{~T} 9 \mathrm{~F}$
ECP can be used as regular method
ECP cannot be used by breast feeding mother

10. Emergency contraceptive pills have varying effectiveness in preventing unwanted pregnancy from 75 to 85 percent depending on the hormonal preparation used. Please indicate which are true.
1 Combined pill ECP is $75 \%$ effective
3 Progestin-only ECP is $75 \%$ effective
2 Combined pill ECP is $85 \%$ effective
4 Progestin-only ECP is $85 \%$ effective

8 Do not know

11. Which ECP has less side effects? (check one that applies)
1 Progestin-only ECP
2 Do not know
2 Combined pills ECP

12. Which of the following side effects are associated with ECP? (check all that apply)
01 Breast tenderness
02 Headache
03 Weakness
04 Nausea and vomiting
07 Insomnia
05 Spotting
10 Cramping and bleeding
08 Fatigue
06 Heavy bleeding
09 Dizziness
88 Do not know

13. Most of these side effects last for? (check one that apply)

01 One day

04 Three days

02 Two days

07 Do not know

05 More than three days 


\section{ECP in the National Program}

\section{Emergency Contraceptive Pills (ECP)}

$\square$ Post-test Questionnaire

Organization:

Designation:

Specialty:

Age:

Male $\square$ Female

1. Which of the following statements describe the purpose of emergency contraceptive pills (ECP) as a contraceptive method? (check one that applies)

1 ECP is used before unprotected intercourse* to avoid unwanted pregnancy

2 ECP is used after unprotected intercourse* to avoid unwanted pregnancy

8 Do not know

2. When will you say unprotected intercourses that have happened require ECP? (check all that apply)

1 One combined oral contraceptive pill was missed in a given cycle

2 Three combined oral contraceptive pills were missed in a given cycle

3 One progestin-only oral contraceptive pill was missed in a given cycle

4 Missed injection due date (also extended 14 days) and had unprotected intercourse

5 Acontraceptive method failed during use (e.g. condom leak or slip)

6 Unprotected intercourse occurred as a result of rape

7 Intercourse without any method

8 Do not know

3. What amount of hormone the combined oral contraceptive pill must contain (Yuzpe regimen) to be effective as emergency contraceptive pill? (check all that apply)

1 At least $0.1 \mathrm{mg}$ of ethinyl estradiol and $0.5 \mathrm{mg}$ of levonorgestrel

2 At least $0.2 \mathrm{mg}$ of ethinyl estradiol and $0.5 \mathrm{mg}$ of levonorgestrel

3 At least 100 microgram of ethinyl estradiol and 500 microgram of levonorgestrel

4 At least 200 microgram of ethinyl estradiol and 1000 microgram of levonorgestrel

8 Do not know

4. What amount of hormone the progestin-only pill regimen must contain to be effective as emergency contraceptive pill? (check all that apply)

1 At least $0.5 \mathrm{mg}$ of levonorgestrel

22 At least $1.5 \mathrm{mg}$ of levonorgestrel

3 At least $0.75 \mathrm{mg}$ of levonorgestrel

8 Do not know

4 At least $1 \mathrm{mg}$ of levonorgestrel

*Unprotected intercourse means intercourse without any contraceptive methods or methods used incorrectly or thought that method used may not work perfectly. 
5. In what way emergency contraceptive pills work. (check all that apply)
1 It prevents ovulation
2 It prevents fertilization
3 It kills spermatozoa
4 It aborts fertilized ovum
5 It delays ovulation
6 It makes uterine cavity unsuitable for ovum
7 It prevents implantation
8 Do not know

6. ECP must be initiated within hours. (check one that apply)
1 Within 24 hours after unprotected sex
2 Within 72 hours after unprotected sex
3 Within 48 hours after unprotected sex
4 Within 96 hours after unprotected sex
5 Within 120 hours after unprotected sex
8 Do not know

7. How many doses of ECP should be taken? (check all that apply)
1 One
3 Three
2 Two
4 Four
8 Do not know

8. What is the interval between doses of ECP? (check all that apply)
16 hours
312 hours
224 hours
5 Not applicable
8 Do not know

9. Below is a list of statements regarding emergency contraceptive pills. Please indicate whether each statement is true or false by circling the correct answer.
a. $\quad 1 \mathrm{~T} \quad 2 \mathrm{~F}$
ECP can be used at any time during the menstrual cycle
b. $3 \mathrm{~T}$
$4 \mathrm{~F}$
ECP is an abortifacient
c. $5 \mathrm{~T}$
6 F
ECP can be used as regular method
d. $\quad 7 \mathrm{~T} \quad 9 \mathrm{~F}$
ECP can not be used by breast feeding mother

10. Emergency contraceptive pills have varying effectiveness in preventing unwanted pregnancy from 75 to 85 percent depending on the hormonal preparation used. Please indicate which are true.

1 Combined pill ECP is $75 \%$ effective

3 Progestin-only ECP is $75 \%$ effective

2 Combined pill ECP is $85 \%$ effective

8 Do not know

4 Progestin-only ECP is $85 \%$ effective

11. Which ECP has less side effects? (check one that applies)
1 Progestin-only ECP
2 Do not know
3 Combined pills ECP

12. Which of the following side effects are associated with ECP: (check all that apply)
01 Breast tenderness
04 Nausea and vomiting
07 Insomnia
10 Cramping and bleeding

02 Headache

05 Spotting

08 Fatigue

88 Do not know
03 Weakness

[06 Heavy bleeding

09 Dizziness 
13. Most of these side effects last for? (check one that apply)
1 One day
3 Three days
02 Two days
8 Do not know
4 More than three days

We will appreciate if you could give your views on the clarity and understanding of the three sessions conducted during the course. Your frank comments will help in improving the quality of training. Please rank accordingly, ' 1 ' for excellent, '2' for very good, '3' for good, '4'for bad, '5'for extremely bad and '8' for do not know.
a. ECPtechnical part
b. Service delivery guidelines
c. Counseling on ECP

Understanding of the presentation?

$1 \longdiv { 3 } 4 \longdiv { 5 } 8$

Any further comments:

\section{Answer Key to the Pre - test and Post - test Questionnaires}

\section{Below are the Correct Answers}

Question 1:2

Question 2:2, 3, 4, 5, 6, 7

Question 3:1,3

Question 4:3

Question 5: 1, 2, 5,6

Question 6:2

Question 7:1,2

Question 8:3,5

Question 9: $a=T, b=F, c=F, d=F$

Question 10: 1,4

Question 11:1

Question 12: 1, 2, 4, 5, 8,9

Question 13:1 


\section{Counseling Skills Checklist}

\section{(INSTRUCTION: While present during service provision, check the following points)}

Supervisor/Monitor Name: Clinic Name:

Provider Name: Date:

\begin{tabular}{|c|c|c|c|}
\hline \multicolumn{2}{|l|}{ Task } & Yes & No \\
\hline \multicolumn{2}{|l|}{ 1. Greeted the client in a friendly, } & & \\
\hline \multicolumn{2}{|l|}{$\begin{array}{l}\text { 2. Aske } \\
\text { that }\end{array}$} & & \\
\hline \multicolumn{2}{|c|}{$\begin{array}{l}\text { 3. Took a brief medical history, which includes information on dates of } \\
\text { unprotected intercourse and last menstrual period? }\end{array}$} & & \\
\hline \multirow[t]{6}{*}{ 4. Told the client about ECP } & When and how to use? & & \\
\hline & How it works? & & \\
\hline & Effectiveness? & & \\
\hline & Not a regular contraceptive method? & & \\
\hline & Will not induce menstruation or abort fetus? & & \\
\hline & Possible side-effects and management? & & \\
\hline \multicolumn{2}{|c|}{ 5. Allowed client to ask questions? } & & \\
\hline \multirow{8}{*}{$\begin{array}{l}\text { 6. Explained how to manage } \\
\text { possible ECPs side-effects }\end{array}$} & Nausea and vomiting & & \\
\hline & $\begin{array}{l}\text { - Reminded client that nausea/vomiting } \\
\text { may occur? }\end{array}$ & & \\
\hline & $\begin{array}{l}\text { - Suggested taking pill(s) after having } \\
\text { some food? }\end{array}$ & & \\
\hline & $\begin{array}{l}\text { - Advised client to repeat the dose if it } \\
\text { is vomited within two hours? }\end{array}$ & & \\
\hline & Irregular bleeding or spotting & & \\
\hline & - Informed that it may occur? & & \\
\hline & - This is a common side effect? & & \\
\hline & - Assured that it should not last long? & & \\
\hline \multicolumn{2}{|c|}{$\begin{array}{l}\text { 7. Told client her menstrual period may be a few days early or late, but most } \\
\text { likely will be on time? }\end{array}$} & & \\
\hline $\begin{array}{l}\text { 8. Reminded client that ECPs ar } \\
\text { Asked client to come back if } \\
\text { can use in the future? }\end{array}$ & $\begin{array}{l}\text { aitable as a regular method of contraception. } \\
\text { ld like to discuss about other methods she }\end{array}$ & & \\
\hline $\begin{array}{l}\text { 9. Explained how to come back } \\
\text { method failure? }\end{array}$ & egular methods or method she used after & & \\
\hline \multicolumn{2}{|c|}{$\begin{array}{l}\text { 10. Demonstrated a non-judgmental attitude and respect for client throughout ECP } \\
\text { service provision? }\end{array}$} & & \\
\hline \multicolumn{2}{|c|}{ 11. Asked the client to summarize the instructions or took feedback? } & & \\
\hline
\end{tabular}




\section{Monitoring and Supervision Checklist}

(INSTRUCTION: During regular field visits check and complete the form. Check the answers given along with the questions. All correct answers are given in bold letters. All incorrect answers should be identified and correct answers should be explained to the providers).

Supervisor/Monitor Name: Clinic Name:

Provider Name: Date:

\section{Knowledge Questions on ECP}

1a. If a woman has unprotected intercourse, what is the chance of her getting pregnant?

Everybody has equal chance of getting pregnant after an unprotected intercourse $=1$

Do not know $=2 \quad$ Give an incorrect answer=3

1b. Are you communicating it to your every family planning client? Yes=1 No=2

2. You have been trained and provided ECP. Could you please tell me when you give ECP to a woman what do you say/advise?

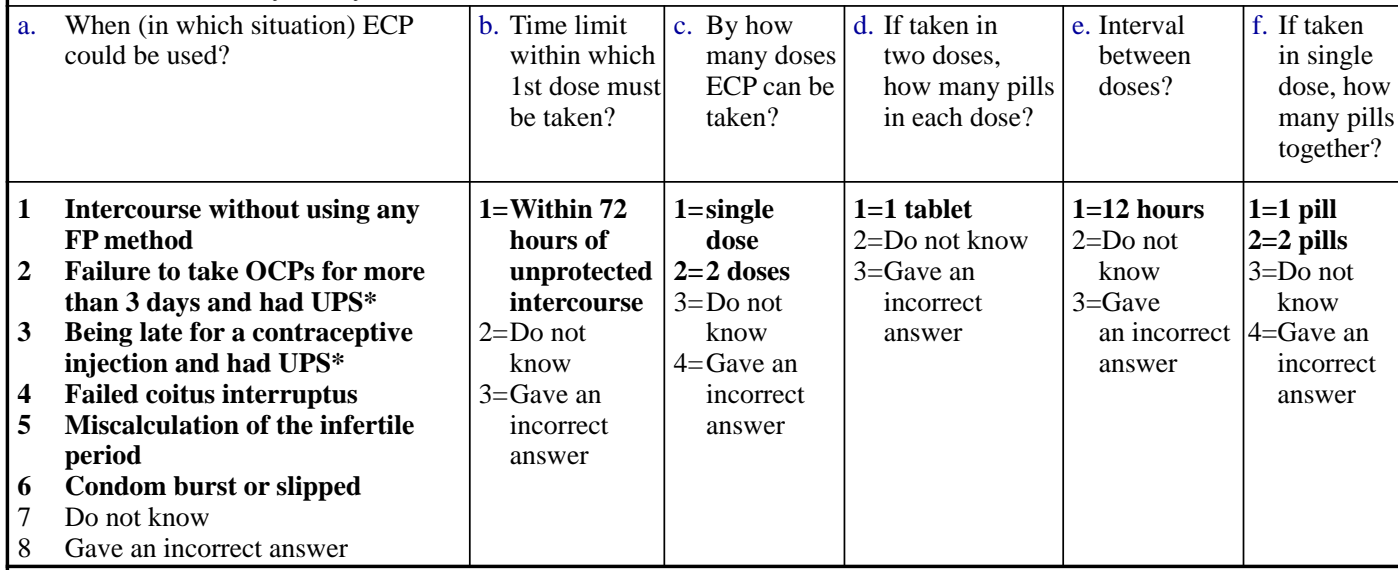

3. A woman who is using pills misses 2 consecutive days, what should she do?

Take 2 pills when she remembers, 2 pills on the next day, then for the rest of the pills take 1 pill a day and use condom $=1$

Do not know $=2 \quad$ Gave an incorrect answer=3

4. A woman who is using pills misses 3 consecutive days, what should she do?

Discontinue pills and use condoms until withdrawal bleeding $=1$

If period does not come, use ECP, continue 1 pill daily after ECP treatment and use condom until next menses $=2$ Do not know $=3$ Gave an incorrect answer $=4$

5. If condom has burst or slipped?

Use ECP, continue condom use and use condom from the next cycle=1

Do not know $=2$ Gave an incorrect answer $=3$

6. If woman has forgotten to take due injection and had intercourse?

Use ECP, use condom until next menses and get injection from the next cycle=1

Do not know $=2$

Gave an incorrect answer $=3$

7. A woman who has requested for ECP, what should she be asked?

Date of last menstrual period $=1 \quad$ Length of women's normal menstrual cycle=2

Timing of all unprotected intercourse during current cycle $=3$ Numbers of hours

since the 1st unprotected sex $=4 \quad$ Do not know $=5 \quad$ Gave an incorrect answer $=6$

* UPS means unprotected sex 


\section{Monitoring Checklist for Training of Trainers \\ At District/ Block Level (Scale up)}

Place of visit: District

Block

Date of visit:

Number of participants present at the beginning of the first session?

Was the inaugural session delayed?

1 Yes

2 No

Time when first working session started at:

Was pre-test conducted?

1 Yes

2 No

Was the overhead projector available?

1 Yes

2 No

Have they used supplied transparencies?

1 Yes

2 No

How was the power supply/electricity? 1 No supply 2 Interrupted 3 Uninterrupted

How was the venue for invited number of trainees? 11 Good 2 Congested

How many resource persons took the sessions?

Did all resource persons come on time?

1 Yes

2 No

Did any participants leave during the session? $\quad 1$ Yes $\quad 2$ No If yes, how many $\square \square$

Please mark the following questions on quality of each session:

\begin{tabular}{|c|c|c|c|c|}
\hline Questions & $\begin{array}{l}\text { ECPTechnical } \\
\text { Part }\end{array}$ & $\begin{array}{l}\text { Service Delivery } \\
\text { Guidelines }\end{array}$ & \begin{tabular}{|c|} 
Counseling on \\
ECP
\end{tabular} & Remarks \\
\hline \multicolumn{5}{|l|}{ a. Session taken by } \\
\hline b. Was the presentation clear & 2 & 2 & 2 & \\
\hline c. Provided adequate information & 2 & 2 & 2 & \\
\hline d. Presenters came prepared & 2 & 2 & 2 & \\
\hline $\begin{array}{l}\text { e. Provided enough time for open } \\
\text { discussion }\end{array}$ & 2 & 2 & 2 & \\
\hline f. Able to clarify trainee's questions & 1 & 2 & 2 & \\
\hline g. Was the interaction good? & 2 & 2 & 1 & \\
\hline
\end{tabular}

Yes $=1, \mathrm{No}=2$

Was post-test conducted?

Yes 1

No 2

Number of participants present at the end of the last session?

Were sessions delayed for any particular individual? $\quad$ Yes $11 \quad$ No 2

Impression on overall quality of training? Very good 1 Good 2 Need improvement 3

Time when session closed at

Please write your descriptive field notes on the training in this page

Name and designation of the monitoring officer: 
